Historic, archived document

Do not assume content reflects current scientific knowledge, policies, or practices. 

United States

Department of

Agriculture

Forest Service

Rocky Mountain

Forest and Range

Experiment Station

Fort Collins,

Colorado 80526

Resource Bulletin

RM-13

ifis

\section{Net Economic Value of Deer Hunting in Idaho}

Dennis M. Donnelly and Louis J. Nelson

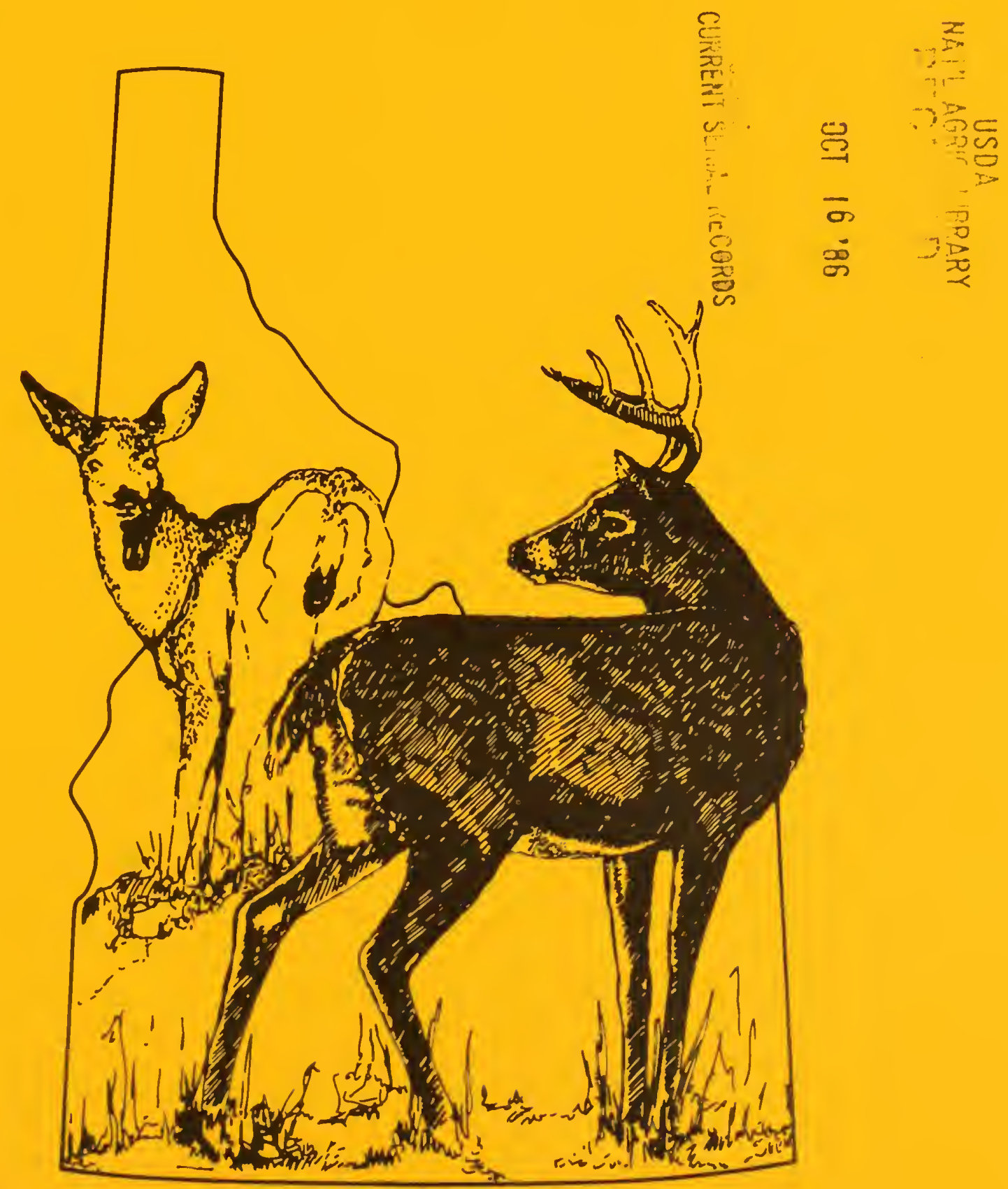




\begin{abstract}
Average net willingness to pay in addition to actual expenditure for deer hunting in Idaho was estimated with the Travel Cost Method at $\$ 50.23$ per trip and with the revised 1983 Contingent Value Method at $\$ 40.09$.
\end{abstract}

\title{
Acknowledgement
}

This study was a cooperative effort of the Idaho Department of Fish and Game, the University of Idaho College of Forestry, Wildlife, and Range Sciences, the USDI Bureau of Land Management and the Fish and Wildlife Service, and the USDA Forest Service. Helpful and constructive comments were received from Michael D. Bowes, Resources for the Future; Richard C. Bishop, University of Wisconsin; Nancy Green and others, USDI Bureau of Land Management; Laurence R. Jahn, Wildlife Management Institute; James A. McDivitt, Thomas J. Mills, Terry Raettig, and Cindy F. Sorg, USDA Forest Service; Rod Olson, USDI Fish and Wildlife Service; Elizabeth A. Wilman, University of Calgary; John B. Loomis, University of California, Davis; and Richard G. Walsh, Colorado State University. 


\title{
Net Economic Value of Deer Hunting in Idaho
}

\author{
Dennis M. Donnelly, Research Forester \\ Rocky Mountain Forest and Range Experiment Station ${ }^{1}$ \\ and \\ Louis J. Nelson, Staff Biologist \\ Idaho Department of Fish and Game
}




\section{Contents}

MANAGEMENT IMPICATIONS .................................

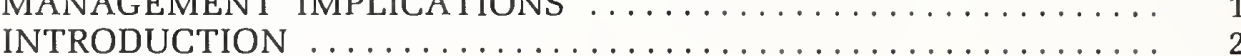

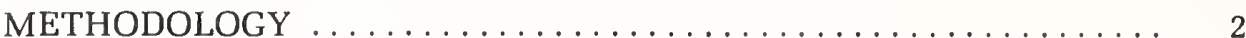

Concepts of Economic Value .................... 2

Measuring Economic Value ...................... 3

The Travel Cost Method (TCM) .................. 3

The Contingent Value Method $(\mathrm{CVM}) \ldots \ldots \ldots \ldots \ldots \ldots \ldots \ldots$

Survey Design .............................. 5

Analysis for TCM ............................ 5

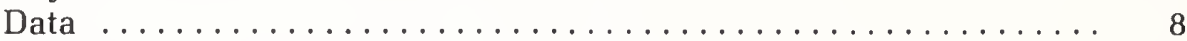

Regression Analysis ......................... 9

Calculation of TCM Benefits .................... 10

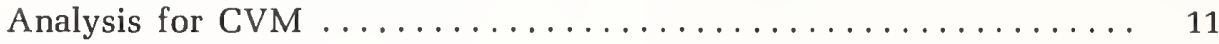

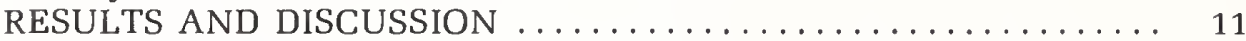

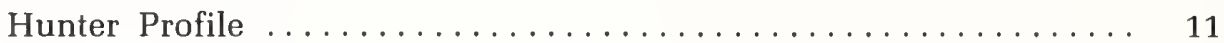

Travel Cost Method ............................ 11

Correlation Analysis .......................... 11

Regression Analysis ........................ 11

Benefit Computation ........................... 12

Contingent Value Method ...................... 13

Comparison of TCM and CVM ................... 13

Comparison With Other Deer Valuation Studies ............ 18

The Substitute Issue .............................. 18

CONCLUSIONS AND RECOMMENDATIONS ................ 19

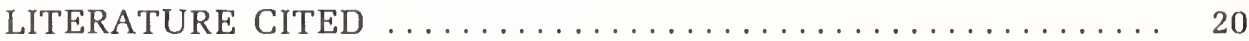

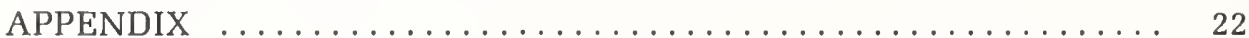

Average and Marginal Consumer Surplus .............. 22

Deer Hunting Survey Forms for 1982 and $1983 \ldots \ldots \ldots \ldots \ldots \ldots 24$

Computation of Benefit Value per WFUD .............. 27

Computation of Cost of Travel .................. 27 


\title{
Net Economic Value of Deer Hunting in Idaho
}

\author{
Dennis M. Donnelly and Louis J. Nelson
}

\section{MANAGEMENT IMPLICATIONS}

Recreation associated with wildlife obviously has economic value. However, opinions on the nature and level of this economic value vary widely, in part because of the different definitions of economic value held by managers, biologists, and economists and in part because of the different methodologies used to estimate economic value. Using results of a state-wide survey, this bulletin describes consumer surplus benefits, one of several categories of economic value associated with deer hunting in Idaho.

Deer hunted in Idaho are primarily whitetail deer (Odocoileus virginianus) in the northern third of Idaho and mule deer (Odocoileus hemionus) in the southern two-thirds of the state. Exceptions do occur to these generalized species locales, but these distinctions are made in the deer management plans in Idaho.

The estimated average net economic value (or consumer surplus) of a deer hunting trip in Idaho is $\$ 50.23$. This is the value to the hunter and to society. This means the average hunter would be willing to pay an additional $\$ 50$ per trip above actual expenditures to continue to have these sites available for deer hunting in Idaho.

Managers, analysts, planners, and others using this and the other information in this bulletin should note its exact nature. The value of a deer hunting experience on a per-trip basis is a weighted average over all deer hunting sites in Idaho. The weighting is on the basis of number of trips to each site. Those sites with more visits, and consequently more consumer surplus, contribute relatively more weight to the average value.

Net economic value per trip can be converted to a value per 12-hour Wildlife and Fish User Day (WFUD). This will facilitate its use in economic efficiency analyses such as FORPLAN or SAGERAM or in investment analyses at the project level. Converting a per trip value to a WFUD value is based on number of days hunted per trip and the number of hours hunted per day. The value of a 12-hour WFUD of deer hunting is $\$ 49$ (see the appendix for computation method).

The values reported above were derived by a demand curve estimating technique called the Travel Cost Method (TCM). The TCM is based on actual hunter participation and statistically infers the amount that a hunter would pay if given the opportunity. In addition, the Contingent Value Method (CVM) was used in the study to elicit "simulated market bids" from hunters. This CVM approach was used to measure the self-assessed net economic value of each trip to individual hunters during the 1982 deer hunting season. The CVM value per trip was $\$ 40.09$ for current conditions associated with deer hunting. This value per trip converts to $\$ 36.08$ per WFUD for deer hunting.
To evaluate multiple-use allocation decisions about resources such as deer hunting, timber harvesting, cattle grazing, or mining, the net economic value per WFUD rather than expenditures is appropriate. The possible applications of these results can be illustrated with a simple example. Assume wildlife biologists estimate a combination of management practices in all hunt areas will result after a time lag of several years in a doubling of the deer population and of harvestable population and, therefore, of hunting opportunities. The long-run improvement in hunting will be translated (and estimated by TCM) into more trips taken by existing hunters and into trips taken by new and former hunters because of the higher quality hunting experience.

Consider just the sampled hunters included in the TCM analysis. Due to doubling their probability of deer harvest, they would take an additional 2,427 trips per hunting season. Their willingness to pay increases $\$ 137,000$. This increase in value is attained after a suitable long-run adjustment period wherein hunters have adjusted their behavior to account for increased harvest potential.

If the management change and the resulting deer herd increase were to happen uniformly over all hunting sites in Idaho, the sample-based value $(\$ 137,600)$ would be expanded by a factor of approximately 109 (the "blow-up factor" based on sampling rate) to estimate the long-run added value (about $\$ 15$ million) to all deer hunters in Idaho. Economic value of improved deer hunting would be compared to the net economic value of any forgone benefits of the management program and to its cost. If the economic value of what was gained (about $\$ 15$ million) is greater than the economic value of what was lost, then economic efficiency is improved.

In field studies it is often difficult for biologists to have access to the original TCM data, the TCM demand curve, and a computer program to calculate benefits of a quality-induced change in net economic benefits. Often biologists will be able to translate the change in wildlife habitat or populations into an increase in the supply of hunting trips of constant quality. The economic benefit of the added hunting trips can be approximated by multiplying the increase in number of trips by the average net value per trip. For example, figure 1 shows there is a demand for 2,427 additional trips, which, at the average net value of $\$ 50.23$ per trip, yields $\$ 121,908$. This amount is reasonably close to the amount estimated above via formal TCM methods.

Evaluations of benefits of improved deer habitat do not necessarily flow only from more hunter-days in the longrun. An increase in harvestable populations of deer would benefit only current hunters in the short run since it likely takes several years for word of "better" deer hunting to spread from current to potential hunters 
(those who are considering the sport and those who dropped out because hunting conditions were not up to their expectations). The Contingent Value Method, as applied in this study, estimates net economic value to hunters of current and double numbers of deer sightings, assuming no entry of new hunters. This is the area (labeled " 2 ") in figure 1 between demand curve $\mathrm{D}_{1}$ and the vertical line for quantity of trips held constant at the original level (here, 5,666 ).

Readers are cautioned that, in general, economic theory shows that marginal values for deer hunting experiences are the theoretically correct values to use in decisionmaking concerning economic efficiency. There is at least one exception, noted by Mumy and Hanke (1975). The present study, however, estimates average value per trip, not marginal values. The reason these average values can be applied in analyses where only marginal values should be used is that the functional form of the demand curve used in this study has the unique property that, for consumer surplus, marginal value is equal to average value. (See the appendix for a discussion and proof of this proposition.) This property and result do not apply to most other functional forms.

A second caution concerns the geographic scope of analysis where the values shown in this bulletin are appropriate. Because the TCM value is a weighted average over all deer hunting sites, the value could appropriately be used to evaluate the economic efficiency of management actions that uniformly affect all sites. However, values for an entire region and values for any area of

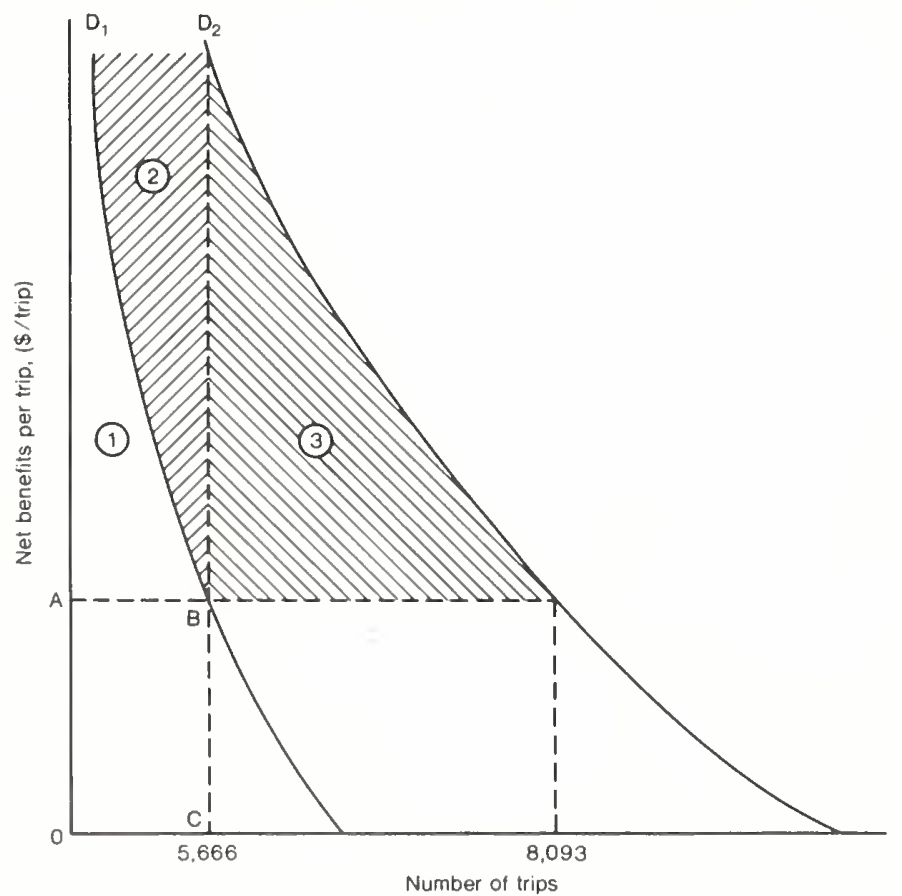

(1) Area 1 is the original estimate of consumer surplus.

(2) After the change, area 2 is the increased benefits estimated by $\mathrm{CVM}$ in the short run.

(3) In the long run, areas 2 and 3 are the total increased benefits estimated by TCM.

Figure 1.- Relationship of TCM and CVM estimates for increases in net economic benefits associated with deer hunting in Idaho. significantly different size are not measurements of the same geographic scope. To the extent that a management action affects selected hunting areas more than others, individual hunting site values, such as those in table 5 , may be more appropriate than the overall values in this bulletin. However, an overall consumer surplus value, such as willingness to pay per trip, may be all that is available, and, for efficiency analyses, these are more tenable than expenditure values.

Finally, caution is indicated when using hunting experience values in analyses that also incorporate values for other resources (e.g., timber or water). Direct comparison of values between resources often is misleading, because the type of value (i.e., average or marginal) or its geographic scope is either unknown or forgotten. For example, it likely is incorrect to compare marginal consumer surplus values for deer hunting from a statewide study to average stumpage values for one forest area surrounded by other forest areas, all of which supply timber to local stumpage markets.

\section{INTRODUCTION}

The value of deer hunting as measured from the economic efficiency view is used in federal land management planning by the USDA Forest Service and the USDI Bureau of Land Management, and for several management purposes by the state of Idaho. To promote a consensus on the economic value of the deer hunting experience in the state of Idaho, several agencies of the Federal Government and the state of Idaho cooperated to empirically estimate the value in Idaho of recreation based on deer hunting. Specifically, the net willingness to pay for the deer hunting experience in Idaho was analyzed to provide a consistent set of dollar values at the state level for the deer hunting experience.

In addition, this study served as a test of the effectiveness of using the Travel Cost Method (TCM) and the Contingent Value Method (CVM) for developing values useful in future planning analyses conducted by the USDA Forest Service.

More specifically, the objectives of the research described in this bulletin are to:

1. Analyze and interpret the relationships between travel costs, expenditures, bids, and the willingness to pay for the deer hunting experience in Idaho.

2. Evaluate the data, the analytical methods, and the results for their potential in various management applications by state and federal agencies.

\section{METHODOLOGY}

\section{Concepts of Economic Value}

Total economic value is the sum of several components-producer expenditures and producer surplus, consumer expenditures and consumer surplus, plus existence, option, and bequest values. Detailed definitions and discussions of these are found in Just et al. (1982) and Randall and Stoll (1983). This bulletin 
focuses on one component-consumer surplus (or net willingness to pay). However, in any resource allocation decisionmaking, other types of value certainly may be considered.

Consumer expenditures are those funds that people spend solely for deer hunting, e.g., transportation costs and hunting (deer) licenses. Sleeping bags and other equipment useful for other activities are not included. For example, in figure 1, consumer expenditures are represented by the area labeled OABC.

Consumer surplus, in contrast, is the area in figure 1 labeled " 1 " below the demand curve $D_{1}$ and above the travel cost expenditure line AB. The concept of consumer surplus arises because, for a demand curve with any downward slope, individuals exist who are willing to pay (1) more than is actually charged for a good, or (2) more than the expenses they actually incur to participate in a recreational activity.

Consumer surplus is the value measured by the techniques used in this study. It is known that a market area exists from which people are drawn solely to hunt deer in Idaho. Further, it is assumed that people traveling from the periphery of the market area would pay no more, if asked, than the amount (the price) already paid in the form of direct deer hunting expenses and traveling expenses from home to the hunt site. Another assumption is that on average the benefits of hunting deer are the same to all participants. Thus, people traveling lesser distances pay a lower price for benefits assumed the same for all. As distances traveled decrease, travel expenditures decrease and surplus is generated relative to those who travel from the periphery of the market area. A measure of the surplus received by participants is their willingness to pay for the experience.

In summary then, the consumer surplus component of economic value is defined in terms of net willingness to pay by the user. For example, the value of forage to ranchers in excess of their costs, the value of water to farmers, and the value of wildlife to hunters-anglers could each be expressed in terms of consumer surplus.

Net willingness to pay (consumer surplus) is the standard measure of value in benefit-cost analyses performed by the U.S. Army Corps of Engineers, Bureau of Reclamation, and the Soil Conservation Service (U.S. Water Resources Council 1979, 1983). Net willingness to pay is the basis of the RPA values used by the Forest Service in forest planning. The rangeland investment policy of the BLM stipulates willingness to pay as the measure of value of all outputs in SAGERAM analysis.

Conversely, use of actual expenditures is not appropriate for valuation of wildlife nor for valuation of other resources (Knetsch and Davis 1966). Expenditures are useful for measuring the effect or impact on local economies of some resource management action. (See Peterson and Brown ${ }^{3}$ for a thorough discussion of the concepts and relationships outlined briefly in this section.)

${ }^{3}$ Peterson, George L., and Thomas C. Brown. 1985. The economic benefits of recreation-Common disagreements and informed replies. Paper prepared for the Southeastern Recreation Research Conference, Myrtle Beach, S. C., February. Proceedings forthcoming.

\section{Measuring Economic Value}

Dwyer et al. (1977) and the U.S. Water Resources Council $(1979,1983)$, Walsh (1983), and Knetsch and Davis (1966) all recommend the Travel Cost Method (TCM) and the Contingent Value Method (CVM) as conceptually correct techniques for empirically estimating users' net willingness to pay.

For hunting, no mechanism currently exists to actually charge more to measure consumer surplus, e.g., by increasing fees. It is assumed, though, that hunters react to increases in travel cost the same as to fee increases. Thus, by hypothetically increasing travel cost we can simulate hunter reaction and estimate willingness to pay. This is the basis of the Travel Cost Method (TCM).

In contrast, the Contingent Value Method (CVM) measures net surplus by directly asking participants how much more they would be willing to pay, above expenditures, to enjoy the experience. Thus, both the TCM and CVM are used to estimate the net consumer surplus above costs.

\section{The Travel Cost Method (TCM)}

The TCM has several variations, depending on the availability of data and the goals of the study. For more detail about TCM in general, see Rosenthal et al. (1984). In the deer study, a Regional Travel Cost Model (RTCM) was constructed because of multiple origins and sites. The dependent variable is trips per capita. The "per capita" specification is used to adjust for population differences between counties of visitor origin. As Brown et al. (1983) show, trips per capita takes into account both the number of visits as a function of distance and also probability of visiting the site as a function of distance.

Use of the TCM depends on several assumptions (Rosenthal et al. 1984). To interpret travel cost and travel time as the price of taking part in hunting, key variable costs that depend on distance traveled must be measurable. Also, travel must be undertaken exclusively to partake in the activity. In contrast, if people embark on a trip for several purposes (viz., sightseeing, visiting people, hunting), variable travel costs are expended for joint production of several goods. Allocating some portion of expenses to hunting is often difficult in such multiple purpose trips. Haspel and Johnson (1982) suggest that benefits for an activity are overestimated to the degree that multidestination trips make up the data set. In addition, travel itself should not provide any benefits. Also, the opportunity cost of travel time must be known.

The list of possible independent variables includes a surrogate for price, i.e., distance, hunt area characteristics, measures of substitutes, and demographic characteristics of hunters. Given the constraints on length of the hunter survey, and limitations on time for data analysis, a relatively simple RTCM was estimated. The basic model was as follows:

$\begin{aligned} \frac{\text { TRIPS } \mathrm{ij}}{\text { POP }_{\mathrm{i}}}=\mathrm{b}_{\mathrm{o}}-\mathrm{b}_{1} \text { DISTANCE }_{\mathrm{ij}}+\mathrm{b}_{2} \text { QUALITY }_{\mathrm{j}} & -\mathrm{b}_{3} \text { SUBSTITUTE INDEX }_{\mathrm{i}}+\mathrm{b}_{4} \text { INCOME }_{\mathrm{i}}\end{aligned}$ 
where

TRIPS $_{i j}=$ number of trips taken from origin i to hunt area $\mathrm{j}$

$\mathrm{POP}_{\mathrm{i}}=$ population in 1980 of origin $\mathrm{i}$ NOTE: The quotient of these first two quantities is the ratio, trips per capita, from origin to hunt area.

DISTANCE = round-trip distance from origin $\mathrm{i}$ to hunt area $\mathrm{j}$

QUALITY = a measure of hunting quality at area j

SUBSTITUTE INDEX = a measure of the cost and quality of substitute hunt areas relative to the one under consideration, i.e., area $\mathrm{j}$

INCOME $=$ a per capita measure of the ability of residents in origin i to incur costs for recreation; serves as a proxy for other taste variables

$\mathrm{b}_{0}-\mathrm{b}_{4}=$ coefficients to be estimated; the algebraic signs indicate the expected relationship of each independent variable with trips per capita.

Equation [1] specifies the per capita demand curve for hunting areas in the region. By setting the quality measure at a value associated with a specific area, the general RTCM regression model estimates the demand curve for that area. Thus, recreation visitation patterns for all areas in the region can be modeled with one equation. Equation [1] states that trips per capita from origin $i$ to area $j$ is a function of the distance from origin $i$ to area j, quality of area j, the substitute areas available to origin $\mathrm{i}$, and the per capita income of residents of origin $i$.

Once the per capita demand curve is specified, the second stage demand curve is then calculated. This second stage demand curve relates total trips to an area from all origins as a function of hypothetical added cost, as measured by distance. The hypothetical added distance is converted to travel costs (in dollars) so the area under the second stage demand curve represents net willingness to pay. Willingness to pay is a net value since only the hypothetical added cost is reflected in the second stage demand curve, not the original travel costs. The reader unfamiliar with this process is encouraged to see Clawson and Knetsch (1966) or Dwyer et al. (1977).

Last, the total consumer surplus for all areas as measured by net willingness to pay can be converted to economic value per trip by dividing by the number of trips taken at zero added cost. Consumer surplus per day may also be computed by dividing consumer surplus per trip by estimated average days per trip for the recreationists sampled.

The estimate of net willingness to pay is the end result of a series of mathematical and statistical operations on the aggregated data. One item of interest about estimated net willingness to pay is the sensitivity this estimate exhibits in response to variation within the Travel Cost Model. This variation is seen initially in the computed statistical confidence interval associated with the estimate of each coefficient of the visits per capita regression model, i.e., the first stage demand curve. Conceptually, this variation is carried through all the steps described above, including formation of the second stage demand curve and the subsequent integration under it. Thus, it is logical to talk about variation associated with estimated net willingness to pay.

However, the statistical properties of the estimators of such variation are as yet undefined and the problem is theoretically difficult. ${ }^{4}$ In spite of this situation, certain aspects of sensitivity may reveal information about the variability of benefit estimates. Specifically, for this research, a "sensitivity interval" was defined. This interval is for estimated benefits measured by willingness to pay and describes the upper and lower bounds of the benefit estimate when the regression coefficient of distance is varied to the upper and lower bounds of its confidence interval.

For example, the computer program that computes benefits is run three times, once with the distance coefficient at its best unbiased level, once with it at the lower level of its $95 \%$ confidence interval, and once with the distance coefficient at the upper level of its $95 \%$ confidence interval. The three estimates of benefits related to deer hunting indicate how benefits vary with respect to variation in the coefficient associated with distance. Distance is chosen specifically because increased increments of this independent variable measure additional cost hypothetically incurred by hunters. Later in this report these sensitivity intervals are compared to the confidence intervals derived from contingent valuation (CVM). This comparison is not a formal statistical procedure per se, but it does furnish the reader with a subjective but quantitative measure of the relative ranges in estimates produced from each method.

\section{The Contingent Value Method (CVM)}

The CVM is also known as the "direct method" since the interviewer directly asks recreationists what they would be willing to pay to hunt at a particular area. The main question here is the individual's net willingness to pay for hunting at an area, relative to some alternative site. An alternative typically valued involves the addition or elimination of one or more hunt areas, not the elimination of hunting in general. Although CVM relies on responses to hypothetical questions, research by Bishop and Heberlein (1979) and Brookshire et al. (1982) indicates that rather than overstating the willingness to pay, CVM generally provides conservative estimates.

CVM is implemented with a bidding game approach and there are several ways to ask bidding game questions. Because a telephone interview was used in this study, the "iterative" technique was chosen. The iterative technique involves repeatedly asking if the person would pay successively higher amounts of money; the maximum amount value is recorded.

\footnotetext{
${ }^{4}$ Personal communication from Rudy King, Biometrician, Rocky Mountain Forest and Range Experiment Station.
} 
Another aspect of survey design is to identify the appropriate "payment vehicle" to elicit the money bid. For example, one can use entrance fees, license fees, taxes, trip costs, or payment into a special fund. In this study, trip cost was used as the payment vehicle because it was fairly neutral and familiar to the respondents. Entrance or license fees may provoke an emotional reaction biasing answers, especially if the questions are asked by a State Fish and Game agency. The text of the two survey questionnaires used in this study is reproduced in the appendix.

The analysis of CVM results is straightforward. Generally the mean willingness to pay is calculated once outliers and protest bids are removed. It should be noted that question design is vital to obtaining a true CVM measure of value. Since CVM is based on a direct measure of value, a poor survey design will render useless results. This means including a protest mechanism in the survey. This mechanism allows differentiating between legitimate bids and bids made in protest to the survey itself, not the resource in question.

Before calculating mean willingness to pay, the data must be screened to remove outliers. In this study, individuals who either could not or would not place a value on the experience were deleted from the sample.

\section{Survey Design}

The population considered for this study included both resident and nonresident hunters having an Idaho deer license in 1982. The overall sampling rate for rifle hunters was $0.917 \%$, or 1,445 individuals. An additional small number purchased either an archery or muzzleloader stamp required for participation in those hunts. See table 1 for details on the types of licenses and the sampling rate for each type.

The Idaho Department of Fish and Game (IDFG) annually surveys hunters to obtain information about big game harvest. IDFG personnel in cooperation with the College of Forestry, Wildlife, and Range Sciences at the University of Idaho collected economic data in conjunction with the annual survey. Telephone surveyors contacted hunters in January and February 1983 for information about the 1982 deer hunting season. A summary of the data collected is shown in table 1 .

Surveyors contacted archery and muzzleloader stamp holders after completing the survey of rifle license holders. No data are available about the proportion of archery and muzzleloader stamp holders who hunted for deer because these stamps are sold separately and not related to the sale of the required species-specific licenses. What information is available on these hunters is included in table 1.

The survey (text in appendix) was designed to collect information on each deer hunting trip made during the 1982 hunting season by every hunter contacted. This included such information as the hunt unit visited (fig. 2), number of animals seen, number of licensed hunters in party, and expenditures.

For the TCM analyses, trips were screened to insure hunting was the primary purpose of the trip and that trips were taken to a single destination. The intent was to eliminate from the TCM analyses multidestination and multipurpose visits that were not dependent on the availability of hunting.

The respondents were asked to report the round-trip distance traveled to each site visited. This variable became the price surrogate. Although Brown et al. (1983) noted that recall of distance may be in еггог, these authors also noted that use of zonal TCM minimizes the effect of the error on coefficient estimates.

In the CVM portion of the survey conducted for the 1982 season, the bidding question was asked for each deer hunting trip made to estimate its value. This method combines the open-ended and the iterative bidding procedures. Respondents were asked if and how much more they would have been willing to pay for the trip. If respondent indicated a specific amount (open-end), the value was recorded. If not, the iterative technique was implemented; the respondent was asked if the trip was worth successively higher amaounts, expressed in increments of $10 \%$, until a maximum value was elicited. This value was recorded. Infinite values were not used in data analysis. If the respondent said the trip was not worth more, no protest question was asked in the 1982 survey.

The questions were revised and the survey for CVM repeated for the 1983 deer hunting season. In this survey, iterative bidding was employed rather than an openended willingness to pay question, but respondents were queried only about the last hunting trip of the season. (The 1983 survey instrument is also reproduced in the appendix). Results and discussion of these two surveys are given later.

Information on the number of days hunted on a trip and the number of hours hunted per day was also elicited from the respondent in both the 1982 and 1983 surveys. This was used to convert TCM and CVM dollar values to a value per day and also a value per 12-hour Fish and Wildlife User Day (WFUD) as required for Forest Service analyses. The computation procedure for these values is in the appendix.

\section{Analysis for TCM}

The general flow of analysis of TCM data progresses from elementary analysis to computation of benefits via a series of related steps. This approach provided for feedback and iterations when results indicated that further analysis of previous steps would increase knowledge of data relationships. In general, the analysis progressed as follows:

1. Computation of elementary statistics for all trips and for trips separated into logical groups;

2. Analysis of all variables to identify those that could logically be related to trips per capita in an economic sense;

3. Correlation analysis of the most promising variables to identify those that were significantly associated with trips per capita;

4. Regression runs with various combinations of explanatory variables; 
Table 1.-Profile of Idaho deer hunters, 1982 - License cost and sample information. (Sample size in parentheses)

\begin{tabular}{|c|c|c|c|c|c|c|c|c|}
\hline \multirow[b]{2}{*}{$\begin{array}{l}\text { Survey } \\
\text { data }\end{array}$} & \multicolumn{5}{|c|}{ Rifle license holders } & \multirow{2}{*}{$\begin{array}{l}\text { Archery } \\
\text { stamp } \\
\text { holders }^{3}\end{array}$} & \multirow{2}{*}{$\begin{array}{l}\text { Muzzleloader } \\
\text { stamp } \\
\text { holders }^{3}\end{array}$} & \multirow{2}{*}{$\begin{array}{c}\text { All Idaho } \\
\text { deer } \\
\text { hunters }\end{array}$} \\
\hline & Resident $^{1}$ & $\begin{array}{l}\text { Senior } \\
\text { resident }{ }^{1}\end{array}$ & Nonresident $^{2}$ & $\begin{array}{l}\text { Nonresident } \\
\text { backcountry }\end{array}$ & Total & & & \\
\hline License \& tag cost & 13.00 & N/C & 126.00 & 126.00 & & 5.50 & 5.50 & \\
\hline Number sold & 142,663 & 4,301 & 9,561 & 999 & 157,524 & -4 & - & \\
\hline Percent surveyed & 0.925 & 0.535 & 0.847 & 2.102 & 0.917 & - & - & \\
\hline Number contacted & 1,320 & 23 & 81 & 21 & 1,445 & 195 & 262 & 1,902 \\
\hline $\begin{array}{l}\text { Number of hunters } \\
\text { in data set }\end{array}$ & 1,300 & 3 & 69 & 11 & 1,383 & 186 & 115 & 1,684 \\
\hline $\begin{array}{l}\text { Number of trips } \\
\text { taken by sampled } \\
\text { individuals }\end{array}$ & 3,759 & 3 & 77 & 11 & 3,850 & 1,376 & 285 & 5,511 \\
\hline Mean trips per hunter & 2.892 & 1.000 & 1.116 & 1.000 & 2.784 & 7.398 & 2.478 & 3.273 \\
\hline $\begin{array}{l}\text { Motor vehicle miles } \\
\text { traveled }\end{array}$ & $\begin{array}{c}78 \\
(3,627)\end{array}$ & - & $\begin{array}{r}1,421 \\
(75)\end{array}$ & $\begin{array}{c}1,063 \\
(10)\end{array}$ & - & $\begin{array}{r}90 \\
(1,368)\end{array}$ & $\begin{array}{c}136 \\
(285)\end{array}$ & $\begin{array}{c}105 \\
(5,368)\end{array}$ \\
\hline $\begin{array}{l}\text { Small plane } \\
\text { miles traveled }\end{array}$ & $\begin{array}{l}150 \\
(11)\end{array}$ & - & $\begin{array}{r}340 \\
(4)\end{array}$ & $\begin{array}{r}175 \\
(2)\end{array}$ & - & - & - & $\begin{array}{l}197 \\
(17)\end{array}$ \\
\hline $\begin{array}{l}\text { Airline } \\
\text { miles traveled }\end{array}$ & - & - & & $\begin{array}{r}2,300 \\
(2)\end{array}$ & - & - & - & $\begin{array}{r}2,300 \\
(2)\end{array}$ \\
\hline $\begin{array}{l}\text { Composite routine } \\
\text { transport }\end{array}$ & $\begin{array}{c}76 \\
(3,759)\end{array}$ & - & $\begin{array}{c}1,402 \\
(77)\end{array}$ & $\begin{array}{l}1,416 \\
(11)\end{array}$ & - & $\begin{array}{c}90 \\
(1,376)\end{array}$ & $\begin{array}{c}136 \\
(285)\end{array}$ & $\begin{array}{c}104 \\
(5,511)\end{array}$ \\
\hline Cost per mile & 0.218 & - & 0.176 & 0.227 & - & 0.178 & 0.159 & 0.183 \\
\hline $\begin{array}{l}\text { Jet boat } \\
\text { miles traveled }\end{array}$ & $\begin{array}{c}6 \\
(3)\end{array}$ & - & - & - & - & $\begin{array}{c}125 \\
(3)\end{array}$ & $\begin{array}{l}20 \\
(2)\end{array}$ & $\begin{array}{l}54 \\
(8)\end{array}$ \\
\hline $\begin{array}{l}\text { Backpack } \\
\text { miles traveled }\end{array}$ & $\begin{array}{c}6 \\
(103)\end{array}$ & - & - & $\begin{array}{c}9 \\
(7)\end{array}$ & - & $\begin{array}{c}5 \\
(16)\end{array}$ & $\begin{array}{l}5 \\
(5)\end{array}$ & $\begin{array}{c}6 \\
(131)\end{array}$ \\
\hline $\begin{array}{l}\text { Horseback } \\
\text { miles traveled }\end{array}$ & $\begin{array}{c}18 \\
(209)\end{array}$ & - & $\begin{array}{l}30 \\
(5)\end{array}$ & $\begin{array}{c}12 \\
(13)\end{array}$ & - & $\begin{array}{l}23 \\
(24)\end{array}$ & $\begin{array}{c}14 \\
(21)\end{array}$ & $\begin{array}{c}18 \\
(275)\end{array}$ \\
\hline $\begin{array}{l}\text { Hours per } \\
\text { day hunting }\end{array}$ & $\begin{array}{c}6.34 \\
(3,759)\end{array}$ & - & $\begin{array}{c}7.97 \\
(77)\end{array}$ & $\begin{array}{c}8.36 \\
(11)\end{array}$ & - & $\begin{array}{c}7.01 \\
(1,376)\end{array}$ & $\begin{array}{l}7.20 \\
(285)\end{array}$ & $\begin{array}{c}6.58 \\
(5,508)\end{array}$ \\
\hline Days per trip & $\begin{array}{c}1.79 \\
(3,759)\end{array}$ & - & $\begin{array}{c}6.00 \\
(77)\end{array}$ & $\begin{array}{c}8.45 \\
(11)\end{array}$ & - & $\begin{array}{c}1.83 \\
(1,376)\end{array}$ & $\begin{array}{l}1.78 \\
(285)\end{array}$ & $\begin{array}{c}1.87 \\
(5,508)\end{array}$ \\
\hline $\begin{array}{l}\text { Number deer seen } \\
\text { per trip }\end{array}$ & $\begin{array}{c}6 \\
(3,759)\end{array}$ & - & $\begin{array}{c}44 \\
(77)\end{array}$ & $\begin{array}{c}29 \\
(11)\end{array}$ & - & $\begin{array}{r}8 \\
(1,376)\end{array}$ & $\begin{array}{c}32 \\
(285)\end{array}$ & $\begin{array}{c}3 \\
(5,511)\end{array}$ \\
\hline Success this trip ${ }^{5}$ & $\begin{array}{c}1.10 \\
(3,759)\end{array}$ & - & $\begin{array}{c}1.43 \\
(77)\end{array}$ & $\begin{array}{c}1.45 \\
(11)\end{array}$ & - & $\begin{array}{c}1.00 \\
(1,376)\end{array}$ & $\begin{array}{l}1.15 \\
(285)\end{array}$ & $\begin{array}{c}1.09 \\
(5,511)\end{array}$ \\
\hline $\begin{array}{l}\text { Number of people } \\
\text { in a vehicle }\end{array}$ & $\begin{array}{c}2.69 \\
(3,759)\end{array}$ & - & $\begin{array}{c}3.13 \\
(77)\end{array}$ & $\begin{array}{c}2.64 \\
(11)\end{array}$ & - & $\begin{array}{c}2.22 \\
(1,376)\end{array}$ & $\begin{array}{l}2.11 \\
(285)\end{array}$ & $\begin{array}{c}2.54 \\
(5,511)\end{array}$ \\
\hline Travel, Dollars & $\begin{array}{c}17 \\
(3,305)\end{array}$ & - & $\begin{array}{l}246 \\
(76)\end{array}$ & $\begin{array}{l}321 \\
(11)\end{array}$ & - & $\begin{array}{c}16 \\
(1,369)\end{array}$ & $\begin{array}{c}22 \\
(274)\end{array}$ & $\begin{array}{c}19 \\
(5,511)\end{array}$ \\
\hline Food ${ }^{6}$, Dollars & $\begin{array}{c}13 \\
(2,753)\end{array}$ & - & $\begin{array}{l}126 \\
(73)\end{array}$ & $\begin{array}{c}206 \\
(10)\end{array}$ & - & $\begin{array}{c}12 \\
(1,251)\end{array}$ & $\begin{array}{c}16 \\
(215)\end{array}$ & $\begin{array}{c}15 \\
(4,305)\end{array}$ \\
\hline Lodging ${ }^{6}$, Dollars & $\begin{array}{c}25 \\
(10)\end{array}$ & - & $\begin{array}{c}77 \\
(27)\end{array}$ & $\begin{array}{l}73 \\
(4)\end{array}$ & - & $\begin{array}{l}18 \\
(9)\end{array}$ & $\begin{array}{l}88 \\
(4)\end{array}$ & $\begin{array}{c}58 \\
(54)\end{array}$ \\
\hline Guide $^{6}$, Dollars & $\begin{array}{l}20 \\
(2)\end{array}$ & - & $\begin{array}{r}1,205 \\
(10)\end{array}$ & $\begin{array}{r}1,267 \\
\text { (3) }\end{array}$ & - & - & - & $\begin{array}{r}1,087 \\
(16)\end{array}$ \\
\hline Trip, Dollars & $\begin{array}{c}26 \\
(3,440)\end{array}$ & - & $\begin{array}{c}546 \\
(77)\end{array}$ & $\begin{array}{l}880 \\
(11)\end{array}$ & - & $\begin{array}{c}27 \\
(1,373)\end{array}$ & $\begin{array}{c}35 \\
(277)\end{array}$ & $\begin{array}{r}37 \\
(5,181)\end{array}$ \\
\hline
\end{tabular}

\footnotetext{
${ }^{1}$ License $=\$ 6.50 ;$ big game animal tag $=\$ 6.50$; controlled hunt permit fee, if applicable $=\$ 3.50$. N/C $=$ no charge.

${ }^{2}$ License $=\$ 75.50$; big game animal tag $=\$ 50.50$; controlled hunt permit fee, if applicable $=\$ 3.50$.

${ }^{3}$ Both residents and nonresidents hunting with these weapons must purchase the appropriate stamp in addition to applicable license and tag.

${ }^{4}$ Information not available.

${ }^{5}$ This variable is coded as 1.0 no success, or 2.0 success; a value of 1.50 means half of the respondents trips resulted in a deer kill.

${ }^{6}$ Not all hunters purchased this item. The mean is based on only those hunters that purchased the item.
} 


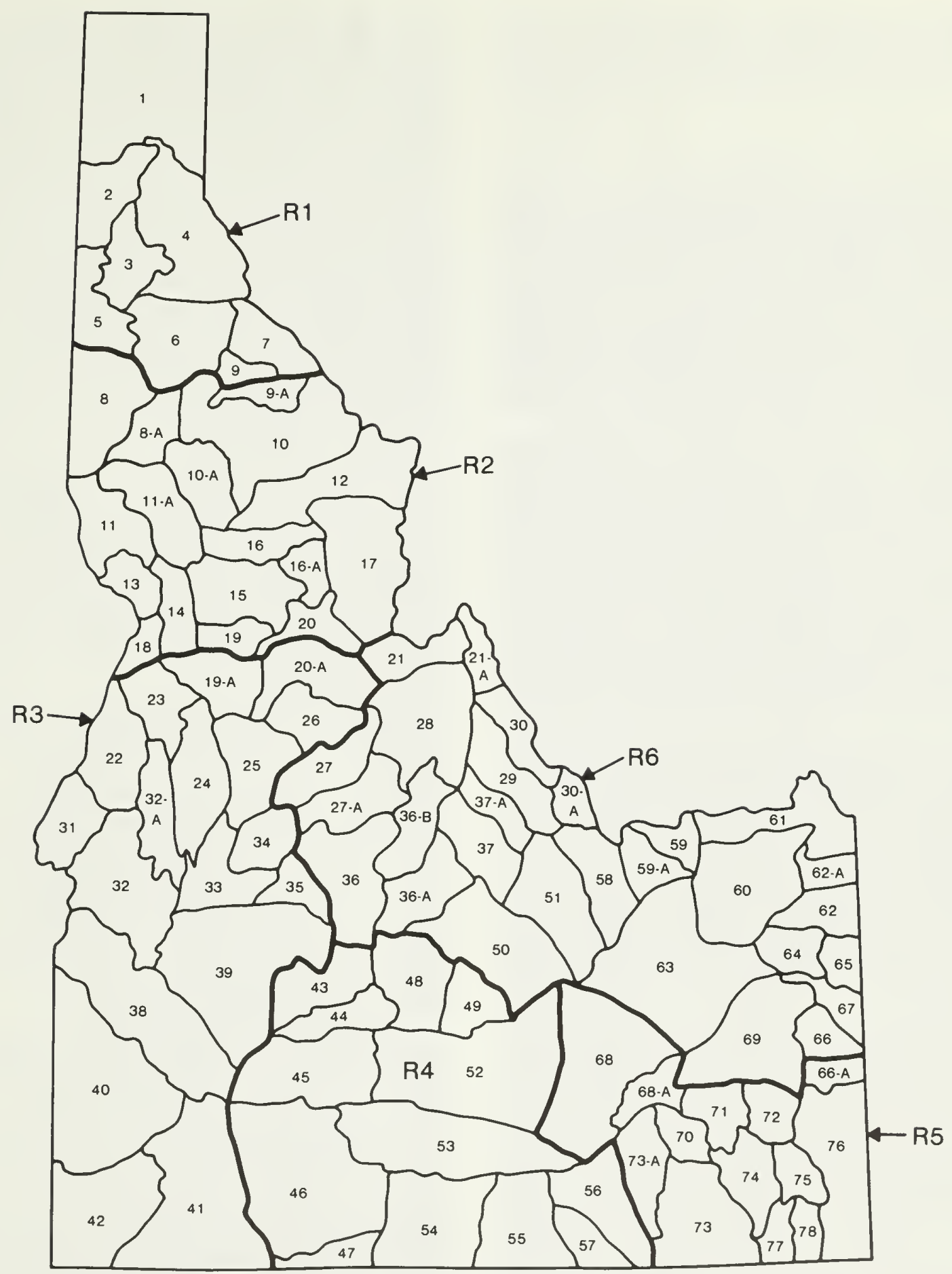

Figure 2. -Big game management unit and regional boundaries established by the Idaho Department of Fish and Game

5. Identification of promising regression runs based on economic theory and statistical significance;

6 . Testing of promising regression runs in the TCM benefits computation computer program;

7. Compilation of benefits estimates and comparisons with each other and with various tests of reasonability.

Several economic assumptions for the TCM were pointed out earlier. In addition, statistical assumptions that apply to estimation of any demand curve are also important (Rosenthal et al. 1984). Sufficient variation must exist in the data in order to statistically identify the demand function. In practice, people who take part in the activity must originate in areas diverse enough to provide a range of distances. In order to get unbiased estimates, all relevant variables that affect demand must be properly specified in the regression. However, even though many variables are commonly candidates for inclusion, usually only a few variables are important when tested statistically. Finally, analysts assume that no short-

7 
age exists for the good in question. This condition means that all demand at a given price can be satisfied. Consequently, no portion of demand is hidden or unobservable.

\section{Data}

For TCM analysis, the individual cases were grouped by county or, in some cases at longer distances, county groups. Within the state of Idaho and for bordering counties of surrounding states, county level specification was used. Groups were developed for counties not immediately adjacent to Idaho in neighboring states. Beyond this region, states were the unit of grouping. Trips per capita from each group of hunter origin could be calculated by dividing population into trips originating from a state or county group.

This technique of considering county group and state populations as the basis for per capita computations mitigates the effect of leaving out blocks of population as distances and geographic агеa increase away from specific sites. Obviously as distance from a site increases, candidate origins are spread over an area that increases quadratically. Even if no trips from a given origin were included in the sample, it is likely that almost every county in Idaho supplied some hunters to many hunt areas. The regional travel cost approach in effect accounts for origins from which trips may originate but that are not sampled.

Once data were aggregated, measures of substitute site attractiveness and site quality were calculated. Past apргоaches used exogenous information on physical characteristics of the site under study and substitute sites. Because this analysis was in many respects a prototype analysis to evaluate the effectiveness of TCM and because of the volume of the data, measures of site quality and substitute sites were limited to data contained in the survey and harvest data supplied in the annual IDFG harvest report.

Hunting "quality" is a concept with many facets. In at least one study success ratio was an important determinant of the willingness to pay for deer hunting in Colorado (Miller et al. 1977). Miller also found that willingness to pay decreased as hunter density increased. However, there were wide differences in these general findings depending on the type of hunter, i.e., resident ог nonresident rifle, archery, muzzleloader, etc. A later study of deer hunters on private land in Colorado showed these same relationships (Gwynn and Schmidt 1984). Consistent with studies such as these, several site quality measures were formulated to reflect hunting quality. The variable, total harvest in 1981 , was significant in the regression analysis. Those site quality variables tested but found to be insignificant in regression analysis included total animals seen, hunters рег square mile in 1981, harvest per square mile, total animals seen per day, average number of days hunted, average number of hours hunted and hunter days per square mile. Although all these variables аге relevant to management, these data indicate the previous year's harvest is the most statistically important variable of site quality as measured in this study.
Two methods for measuring substitute sites were tested. In the first, for a given hunt area, total animals seen this year (1982) and total harvest at the site last year (1981) were each divided by distance traveled from each origin. The numerator was taken as a measure of hunting quality at the site. The distance variable is related to the cost of obtaining this level of quality at that site. Thus, the substitute measure was in essence total animals seen (or total harvest) per mile traveled. The alternative site, other than the specific hunt area under analysis, that had the greatest total animals seen (total harvest) рег mile traveled, compared to all other sites visited from a given origin, was selected as the best substitute for that origin. However, these substitute measures were not significant in the regression analysis.

The second method for measuring substitute sites was a variation of the first measure. Instead of selecting one substitute site for that origin, the one with the greatest quality per mile, it considered the sum of quality per mile based on all sites visited from a particular origin that had a greater quality per mile than the particular site in question. This measure was felt to reflect the quantity of all alternative sites available to that origin. This substitute measure was tested using the sum of total harvest per mile of higher ratio sites and the sum of total animals seen per mile of higher ratio sites. Neither proved statistically significant.

Because no measure of substitutes was found significant in the regression analysis, the possibility exists that benefit estimates are an overestimate of consumer surplus. Normally, a substitute measure has a negative coefficient, so when substitutes for a given hunt area increase, theoretically trips per capita and consumer surplus should decrease. If substitution effects are, in fact, operating in the Idaho deer hunting system, but cannot be quantified by analysis of available data, then the degree of overestimation is not known; however, later comparison to the CVM results and comparison to other studies may provide some indication.

Income and income squared were tested because of the hypothesis that income has an influence on purchases of trips to a recreation site, although Martin et al. (1974) found income does not necessarily enter in a linear fashion. For example, as income increases hunting activity may increase due to more trips by current hunters or to trips made by new hunters; however, further increases in income do not often result in the same proportional increases in hunting. Income entered into the analysis with a negative coefficient, indicating deer hunting may be considered an inferior good. ${ }^{5}$ Without specific income and hunting preference data for each respondent it is not possible to determine the degree, if at all, to which deer hunting can be considered an inferior good relative to other more expensive and timeconsuming recreational activities such as bighorn sheep or mountain goat hunting. The inferior good relation-

\footnotetext{
${ }^{5}$ This term does not imply inferiority in quality or in any social sense; rather, it merely refers to the economic relationship between quantity demanded and income. Hamburger, for example, is often considered an inferior good in the economic sense, because often as income rises, less hamburger, and possibly more steak, is purchased.
} 
ship may be founded in the correlation between income and distance traveled. ${ }^{6}$ In table 2 , this correlation is +0.4071 , highly significant for these data. The rural areas adjacent to good deer hunting units likely have lower county per capita income relative to more urbanized areas further away. Thus, necessary distance traveled and income tend to increase together. The net effect is that increasing distance is associated with increasing prices paid by hunters to access a given area. And, as noted, income also increases with increasing distance but per capita participation rates decrease, giving the appearance of an inferior good. It is also possible that as income rises, a different form of hunting is demanded, such as special weapons stamps or limited hunt permits in remote areas that involve a longer hunt using more specialized and expensive equipment.

\section{Regression Analysis}

Prior to actually running regression analyses on the computer, the data were checked with an extensive correlation analysis to determine those variables best related to trips per capita. In addition, this analysis also provided information about correlation between potential independent variables so as to minimize the possibility of multicollinearity.

Two basic functional forms have been found useful in previous work-the linear and exponential models.

The linear model is

TPC $=b_{0}+b_{1}$ RTDIST $+b_{2}$ TUHLY $+b_{3}$ INC $+b_{4}$ SUBS

and the exponential model is

$$
\begin{aligned}
& \ln (\text { TPC })=b_{0}+b_{1} \text { RTDIST } \\
+ & b_{2} \text { TUHLY }+b_{3} \text { INC }+b_{4} \text { SUBS }
\end{aligned}
$$

where $\quad$ TPC $=$ trips per capita, i.e., trips from a given origin to a particular hunt area divided by the origin's population

RTDIST $=$ round-trip distance from a particular origin to a particular hunt area

TUHLY = total unit harvest in the previous year (i.e., 1981) in given hunt area

INC $=$ per capita income of a county

SUBS $=$ one of the several substitute indices that were tried.

Several variations or tranformations of the independent variables were tried for each model to achieve the best possible regression equation.

The criteria for judging how well each regression performed were both statistical and empirical. Of course, the regression had to account for a statistically significant amount of variation in the data. The coefficient of multiple determination $\left(\mathrm{R}^{2}\right)$, the $\mathrm{F}$-statistic in an associated analysis of variance, and t-statistics for individual independent variables all helped to determine adequacy. In addition, each regression passing these tests was tested in the computer program that computes willing-

${ }^{6}$ Personal communication from Terry Raettig, Regional Economist, Region 1, USDA Forest Service, Missoula, Mont., August 21, 1984. ness to pay benefits. If actual visits over all hunt areas were estimated within approximately $\pm 10 \%$ by the benefits model, then the regression was a candidate for full consideration.

Bowes and Loomis (1980) argued that unequal sizes of population groups require a weighting factor for avoiding heteroskedasticity and thus improving both benefit and use estimates. This weighting factor on all variables in the linear model (equation [2]), including the dependent variable, is the square root of population. Vaughan and Russell (1982) and Strong (1983), however, show that if the log of visits per capita (i.e., the exponential form, equation [3]) is chosen as the functional form, heteroskedasticity will be so greatly reduced that weighting by square root of population may be unnecessary.

However, the conclusions of the cited authors depends on characteristics of specific data bases. Thus, in this case several criteria important in deciding on the relevance of the regression were examined. First, the Regional Travel Cost Model was intended to estimate benefits accruing from an existing set of sites, not to estimate use at a new site. Therefore, goodness of fit of the model was tested according to the procedures developed by Rao and Miller (1965) to determine whether the natural log of visits per capita or natural log of distance performed best ${ }^{7}$. These test statistics indicated natural log of visits per capita was better. In addition, examination of the residuals showed a random pattern well spread out in terms of positive and negative values and runs of sign. Finally, estimated visits were compared with actual visits. If estimated visits were fairly close to actual visits $( \pm 10 \%)$ the natural log of visits per capita was used rather than Bowes-Loomis (1980) weighting.

Ziemer et al. (1980), Vaughan and Russell (1982), and Strong (1983) contend that because of the pattern by which trips per capita falls off at greater distances and because of the potential for heteroskedastic variances, the functional form with natural log of visits per capita (equation [3]) is preferred to a functional form with either linear visits or natural log of distance. Their point is that either of the latter two functional forms will predict negative visits for a few high cost origins and, because negative visits are contrary to intuition, the natural log of visits per capita functional form is preferable.

Another reason that the exponential functional form may work better here than the other two forms is the possibility of a "switching function" based on distance. ${ }^{8}$ For any given origin, distance to hunt areas is

\footnotetext{
${ }^{7}$ The essential problem in comparing goodness of fit for two regressions like these with differing functional forms is that comparing the residual sums of squares to determine which has the lesser value is not valid because the unit of measurement rather than the functional form is the operative factor in decreasing the sum of squares. However, by standardizing the variables so that variance does not change with measurement units, the two forms may be compared. The comparison of each equation's sum of squares is done by means of a nonparametric ratio test on the sums of squares. The test statistic follows a chi-square distribution with one degree of freedom (Box and Cox 1964). When the test statistic is greater than the chosen critical value, the null hypothesis that the two functions are empirically similar may be rejected.

${ }^{8}$ Personal communication from Elizabeth Wilman, Department of Economics, University of Calgary, Alberta, Canada, August 27, 1984.
} 
Table 2.-Correlations between relevant variables. ${ }^{1}$

\begin{tabular}{|c|c|c|c|c|c|c|c|c|}
\hline \multicolumn{9}{|c|}{ Trips per capita } \\
\hline-0.1517 & \multicolumn{8}{|c|}{ Mean round-trip distance } \\
\hline-0.0991 & $+\underset{* \star}{0.7192}$ & \multicolumn{7}{|c|}{ County population } \\
\hline$-\underset{*}{0.1268}$ & $+\underset{* \star}{0.4071}$ & $+\underset{* \star}{0.4676}$ & \multicolumn{6}{|c|}{ County per capita income } \\
\hline $\begin{array}{c}-0.0632 \\
\text { n.s. }\end{array}$ & $+\underset{* \star *}{0.1724}$ & $+\underset{* \star \star}{0.2045}$ & $+\underset{* * *}{0.1323}$ & \multicolumn{5}{|c|}{ Number of animals seen this trip } \\
\hline+0.0852 & -0.0918 & $\begin{array}{c}-0.0785 \\
\text { n.s. }\end{array}$ & $\begin{array}{c}-0.0610 \\
\text { n.s. }\end{array}$ & $-\underset{*}{0.0840}$ & \multicolumn{4}{|c|}{ Hunter density last year } \\
\hline $\begin{array}{c}+0.0702 \\
\text { n.s. }\end{array}$ & $\begin{array}{c}-0.0145 \\
\text { n.s. }\end{array}$ & $\begin{array}{c}-0.0063 \\
\text { n.s. }\end{array}$ & $\begin{array}{c}+0.0057 \\
\text { n.s. }\end{array}$ & $\begin{array}{c}-0.0244 \\
\text { n.s. }\end{array}$ & $+\underset{* \star *}{0.6672}$ & \multicolumn{3}{|c|}{ Harvest density last year } \\
\hline+0.1069 & $\begin{array}{c}-0.0258 \\
\text { n.s. }\end{array}$ & $\begin{array}{c}-0.0381 \\
\text { n.s. }\end{array}$ & $\begin{array}{c}+0.0156 \\
n . s .\end{array}$ & $\begin{array}{c}-0.0993 \\
\text { n.s. }\end{array}$ & $+\underset{* \star \star}{0.9004}$ & $+\underset{* \star *}{0.5951}$ & \multicolumn{2}{|c|}{ Hunter-day density last year } \\
\hline+0.1267 & $\begin{array}{c}-0.0706 \\
\text { n.s. }\end{array}$ & $\begin{array}{c}-0.0393 \\
\text { n.s. }\end{array}$ & $\begin{array}{c}+0.0151 \\
\text { n.s. }\end{array}$ & $\begin{array}{c}-0.0573 \\
\text { n.s. }\end{array}$ & +0.4742 & +0.4648 & 0.4755 & Total unit harvest last year \\
\hline${ }^{1} T w o-t a$ & test of si & icance: & $\begin{array}{l}35 \% \text { level } \\
39 \% \text { level } \\
99.5 \% \text { leve } \\
=\text { not sig! }\end{array}$ & ant. & & & & \\
\hline
\end{tabular}

likely to be associated with short trips, i.e., 1- or perhaps 2-day trips, until some certain threshold distance is reached. Above this threshold range, trip length to faraway hunt areas is likely to be greater than 1 or 2 days' duration because of cost. Trip length may be one aspect of a much more complex phenomenon regarding the choice of hunting product (e.g., day- or camp-oriented hunting, special weapons hunting) that is sought (Driver 1985). All of this speculation is based on the possibility of the existence of multiple demand curves, one for each type of product. The exponential functional form may fit better than other functions the amalgam of data points generated by surveys such as Idaho's. This survey asked for data based only on the generic activity "deer hunting," rather than any more complex set of activities or products.

\section{Calculation of TCM Benefits}

To calculate the second stage demand curve that is the basis for estimates of consumer surplus, it is necessary to convert distance to dollars. Travel costs to a site are made up of transportation costs and travel time costs. Travel time is included because it is often a limiting factor and acts as a deterrent to visiting more distant sites. In addition, omission of travel time will bias the benefit estimates downwards (Cesario and Knetsch 1970, Wilman 1980).

The value of travel time was set at one-third of the wage rate as prescribed by the U.S. Water Resources Council $(1979,1983)$. This is the mid-point of values of travel time that Cesario (1976) found in his review of the transportation planning literature. It must be kept in mind that the use of one-third the wage rate is not necessarily in- tended to measure wages forgone during the time spent traveling, but rather to include the deterrent effect of scarce time on the decision of which sites to visit. This study used the U.S. Department of Labor estimate of a median wage of $\$ 8.00$ an hour because estimates of individual income were not collected. One-third of this is $\$ 2.67$ per hour. It would have been desirable to use the actual wage rate for deer hunters rather than this $\$ 8.00$ average wage, because these individuals may have incomes different than the general average in their home counties.

Conversion of round-trip mileage to transportation costs was done in three steps. First, mileage was converted to transportation cost per vehicle. This was done based on variable automobile costs, such as gasoline, from the U.S. Department of Transportation (1982). Their estimate for an intermediate size car class was a cost of $\$ 0.135$ per mile in 1982 . With approximately 2.54 hunters per vehicle this standard cost per person was approximately $\$ 0.05$ per mile. A mileage figure for pickup trucks was not available.

Transportation cost also was estimated using the hunters' reported cost per mile rather than the standard cost per mile of $\$ 0.135$. Respondents reported that their share of trip transportation costs, when divided by round-trip distance, equaled approximately $\$ 0.18$ per mile. This may be a more appropriate value to use because it is the price perceived by respondents. That is, the quantity of trips consumed would probably be more closely related to the perceived cost rather than some standardized cost. Additionally, the Department of Transportation figure reflects costs of suburban driving with an intermediate size car. Deer hunting may involve use of a four-wheel-drive pickup, often with a camper shell. Roads traveled would rarely resemble 
those in suburbia. These considerations would raise the transportation costs above that of an intermediate size car.

Increasing the transportation cost per mile from $\$ 0.135$ to $\$ 0.183$ increases total travel cost per person per mile, including travel time, from $\$ 0.12$ to approximately $\$ 0.14$ per person per mile. (See the appendix for exact computations.) The net effect is to now associate the quantity of trips made with a higher price per trip, which translates into a rightward shift in the upper portion of the second stage demand schedule. This shift results in an increase in total and, therefore, per trip consumer surplus.

To provide the most useful information for valuation of Idaho deer hunting and to allow comparison to other studies, net willingness to pay is calculated and presented in the results using both standardized and reported cost. For a given increment in distance or added miles, the transportation cost and value of travel time for the amount of time required to travel that distance increment are added together. This rescales the vertical axis of the second stage demand curve from miles to dollars. The area under the second stage demand curve yields estimated sample consumer surplus. Dividing this by number of sample trips yields estimated consumer surplus per trip.

Finally, whenever entry or license fees are charged for access to public facilities or goods, as for hunting and fishing, the Water Resources Council (1983:78) notes that for economic efficiency analysis such charges should be added to the gross amount of consumer surplus. Although these types of charges are a transfer of consumer surplus from the hunter to the government, they contribute to net social welfare and should be counted in total net willingness to pay. Such fees would be counted as benefits in a benefit-cost analysis. However, these same fees must be prorated over total number of trips taken. The net effect, if any, of including fees for computing benefits per trip, per ordinary day, or per WFUD depends on the fee magnitude and the number of trips taken.

\section{Analysis for CVM}

In the 1982 survey, the mean net willingness to pay was calculated once missing values, outliers, and infinite bids were removed. When asked if a trip was worth more, 88.8\% responded "yes." Any bid greater than $\$ 1,000$ was screened as a possible outlier by looking at the respondent's origin, hunt unit visited, number of hours of hunting, and number of days of hunting. Based on these variables, a subjective decision was made as to the validity of the bid. For the 1983 survey, the improved question format allowed for more objective analysis of the data.

\section{RESULTS AND DISCUSSION}

\section{Hunter Profile}

Table 1 presents a summary profile of the data collected in the 1982 deer hunter survey for the TCM and
CVM analyses. Results are based on 5,511 individual trips taken by 1,684 hunters. Based on these data, hunter behavior appeared to vary somewhat by group. For example, resident rifle hunters and non resident backcountry deer hunters had similar travel costs per mile, which were significantly greater than those for nonresident rifle hunters and primitive weapons hunters. Nonresident hunters stayed afield much longer than residents (6 to 8 days versus 2 days for residents) and took fewer trips than residents. This behavior fits with the concept of a distance-related "switching function" that relates to numbers and lengths of hunting trips. Nonresidents' success rate was considerably greater when considered as a group. Nonresident rifle hunters tended to travel in larger groups and primitive weapons hunters in smaller groups, than typical for regular rifle hunters.

\section{Travel Cost Method}

\section{Correlation Analysis}

Some 90 variables resulted from various data sources and from mathematical transformation of fundamental variables. These were reviewed through the logic of their meaningful association with trips per capita and through a formal correlation analysis. Table 2 shows the correlations for those variables that passed both screens.

All the listed variables are significantly related to trips per capita at least at the $5 \%$ level except for "number of animals seen this trip" and "harvest density last year." Even though these two variables did not pass both the logic and correlation screen, they have merit as potential indexes of attractiveness in their fundamental or transformed states.

\section{Regression Analysis}

The logical analysis and preliminary statistical analysis identified those variables most likely to be strongly associated with trips per capita and, in fact, to have a predictive capacity. Regression analyses were made with both the full equation specified and in stepwise fashion. The functional forms were basically those previously discussed, with some experimental variations.

The form of regression equation that best explains the relationships in the data from several statistical points of view is that of equation 3 , but without the substitute term. The terms in the equation and their associated statistics are shown in table 3. Individual terms are each significant at least at the $5 \%$ level. This exponential model is highly significant with an F-value of 232.9 and with an $\mathrm{R}^{2}$ value of 0.57 .

When tested empirically as a predictor of use over all hunt areas, the equation estimated 5,666 visits for the sample data. Since visits for the data were 5,511, the error in this estimate is $2.81 \%$. Although such a comparison is not a statistically rigorous test, the close comparison is encouraging. Note that the equation does not contain a term for the effect of substitute hunting areas. 
Table 3.- Regression ${ }^{1}$ for trips per thousand people (kilo capita, TPCK). ${ }^{2}$

\begin{tabular}{lllrr}
\hline & & \multicolumn{3}{c}{ Coefficient } \\
\cline { 4 - 5 } Variable & Coefficient & value & standard error & "t" statistic \\
\hline Constant & $b_{0}$ & +3.0984 & 0.4505 & 6.88 \\
RTDIST & $b_{1}$ & -0.002438 & 0.0001546 & -15.77 \\
TUHLY & $b_{2}$ & +0.0004039 & 0.0001235 & 3.27 \\
CPCIN & $b_{3}$ & -0.0008472 & 0.00007400 & -11.45
\end{tabular}

\footnotetext{
1 In the form of equation [3], but without the substitution variable, which was not significant.

${ }^{2}$ All figures shown to four nonzero significant digits except for the $t$ statistics shown to two digits. NOTE: This regression was specified with scaled data for trips per capita such that the dependent variable is actually "log natural of trips per thousand people" or in other words, "trips per kilocapita." This transformation allowed a more useful range of significant digits in computer output.
}

\section{Benefit Computation}

The specified regression is a statistical estimate of the demand curve for a given hunt area from a given origin. Round-trip distance (RTDIST) depends on both origin and destination; county per capita income (CPCIN) depends on the origin; and total unit harvest last year (TUHLY) depends on the destination. When each of these quantities for a given hunt area and orgin are substituted into the equation, the result is an estimate of the quantity (q) of hunting participation (in trips per thousand people) demanded from the given origin, at a price (p) based on the costs of travel from origin to site. This is represented by curve $D_{1}$ in figure 1 , often called the stage I demand curve. For example, in figure 3, curves 1 (a single point), 2, and 3 are stage I demand curves for visits per thousand people to hunt area 5 from Benewah, Kootenai, and Latah counties, respectively. It is likely, though not expressed in our data, that hunters from other origins also visited this particular hunt area.

That portion of the stage I demand curve above the price line, viz, only the part shown in figure 3 , is summed horizontally with all other such demand curve portions

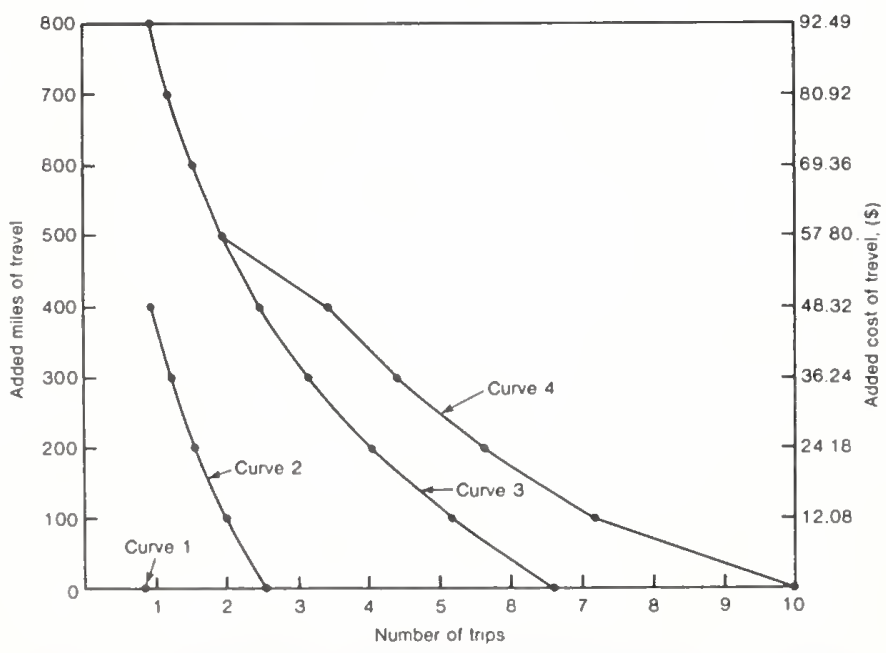

Flgure 3.- Illustration of stage 1 and II demand curves for big game management unit (i.e., hunt unlt) 5 . for origins that provide visitors to a hunt area. The resulting composite curve, here for hunt area 5 , is often termed a stage II demand curve, curve 4 in figure 3 . Because only the portion of the each stage I curve above the price line is summed to make the stage II demand curve, it relates demand and price over and above the price actually paid by travelers from each origin to the specific site. Thus, the entire area under the stage II demand curve, as defined here, is an estimate of the consumer surplus benefits that accrue to the hunt area.

When the benefits for each site are summed over all sites, the total is the consumer surplus generated by the sampled hunters as they visited their respective hunt areas. Total consumer surplus over all hunters would be estimated by multiplying estimated sample benefits by the sample blowup factor, i.e., the inverse of the sampling proportion. For our sample the inverse of the sampling proportion, $0.917 \%$ from table 1 , is 109 .

The associated estimate of consumer surplus per hunting trip is obtained by dividing estimated sample consumer surplus by estimated sample visits. Table 4 summarizes the results of the benefit computations.

These results do not include the per trip share of consumer surplus expended in license fees. Table 1 shows that in 1982 the typical resident rifle deer hunter made 2.887 trips and paid (transferred consumer surplus) $\$ 13.00$ for both a big game license (\$6.50) and a deer tag (\$6.50). In contrast, nonresident hunters typically made one trip and paid much higher fees so, arguably, their license price (transferred consumer surplus) should be included in their overall benefit estimation. However, because resident deer hunters greatly outnumber nonresidents, the general results reported in table 4 are not significantly affected by the magnitude of nonresident fees and so do not include transferred consumer surplus due to license fees.

Complete results of willingness to pay per trip for IDFG management regions, areas, and almost all big game units in Idaho are given in table 5 . As the geographic scope in table 5 becomes smaller, i.e., from region to area to BGMU, the potential variability increases for the corresponding value estimates. Any differences in the amounts shown in tables 4 and 5 for the 
Table 4.-Summary of consumer surplus benefit estimates with TCM under several mileage rate assumptions and with CVM.

\begin{tabular}{|c|c|c|c|c|}
\hline Method & $\begin{array}{c}\text { Total } \\
\text { sample } \\
\text { benefits }\end{array}$ & $\begin{array}{c}\text { Benefits } \\
\text { per } \\
\text { trip }\end{array}$ & $\begin{array}{c}\text { Benefits } \\
\text { per } \\
\text { day }\end{array}$ & $\begin{array}{l}\text { Benefits } \\
\text { per } 12 \cdot h \\
\text { WFUD }\end{array}$ \\
\hline \multicolumn{5}{|l|}{ TCM (1982) } \\
\hline At standard cost, $13.5 \mathrm{~s} / \mathrm{mile}$ & $\$ 247,856$ & $\$ 43.74$ & $\$ 23.39$ & $\$ 42.66$ \\
\hline At overall actual cost, $18.3 \mathrm{c} / \mathrm{mile}$ & 284,627 & 50.23 & 26.86 & 48.99 \\
\hline $\begin{array}{l}\text { For double deer harvest at overall } \\
\text { actual cost, } 18.3 థ / \mathrm{mile}\end{array}$ & 422,227 & ${ }^{1} 52.17$ & 27.90 & 50.88 \\
\hline $\begin{array}{l}\text { At resident rifle hunter actual } \\
\text { cost } 21.8 థ / m i l e\end{array}$ & 311,439 & 54.97 & 30.71 & 58.13 \\
\hline \multicolumn{5}{|l|}{ CVM } \\
\hline 1982 & & ${ }^{2} 24.46$ & \multicolumn{2}{|c|}{ not computed } \\
\hline 1983 & & 40.09 & 19.18 & 36.08 \\
\hline
\end{tabular}

\footnotetext{
${ }^{1}$ This figure is total, not incremental. The increment in benefits per trip for double deer harvest is: $\$ 52.17-50.23=\$ 1.94$.

${ }^{2}$ The CVM survey in 1982 was likely biased downward because of open-ended questions and no mechanism to clarify infinite bids. The revised 1983 survey improved these conditions. (See appendix)
}

statewide summary is a result of rounding in the compilation of table 5 .

Because vehicle cost is one of two components of total cost per person per vehicle mile (CPVM), the benefit estimates are moderately sensitive to changes in the operating cost of the vehicle. Figure 4 shows the relationship between dollars per mile, the independent variable, and vehicle operating cost per mile and benefits for the total sample and for each trip. The relationships are linear and depend on assumptions about time cost and vehicle speed, as discussed earlier. The two graph lines in figure 4 indicate there is not a direct proportional relationship between a vehicle cost charge per mile and the resulting benefit change, viz.

$$
\frac{\$ 0.183 / \text { mile }}{\$ 0.135 / \text { mile }} \neq \frac{\$ 50.23 / \text { trip }}{\$ 43.74 / \text { trip }}
$$

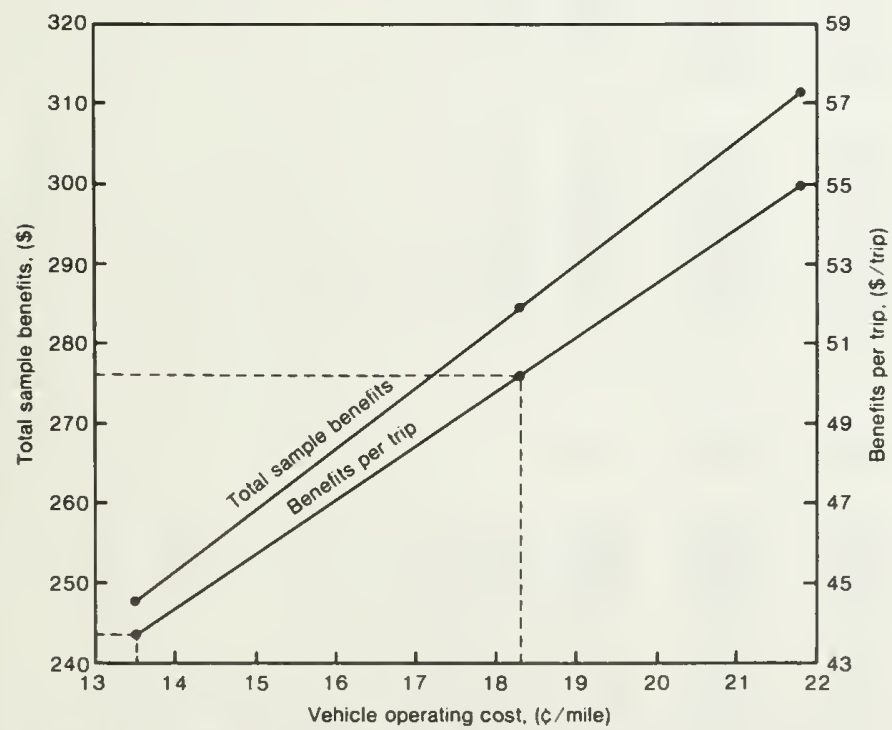

Figure 4. - Effect of vehicle operating cost estimates on total sample benefits and per trip benefits.
Total benefits and benefits per trip increase as unit travel costs increase because hunters who travel longer distances imply they are willing to pay the high prices associated with the distance. Therefore, as the unit cost of travel increases, the consumer surplus also increases. This result occurs because people living closer can enjoy the same hunting areas at relatively less price paid (i.e., distance traveled).

\section{Contingent Value Method}

Compilations of the CVM data show that the mean bid by deer hunters for current conditions during the 1982 hunting season, based on 2,226 valid bids, was $\$ 24.46$ per trip.

CVM data for 1983 show a mean bid value of $\$ 40.09$. The relationship with 1982 CVM data and with TCM is discussed below, as is the variation in the CVM estimates. The 1983 results are more useful because of improvements in the CVM bid questions. In 1983 Idaho deer hunters surveyed in the CVM portion of the study spent 2.09 days per trip in the field, so the CVM-based value per day is $\$ 19.18$. On the basis of a 12-hour Wildlife and Fish User Day (WFUD), the value would be \$36.08, because Idaho deer licensees hunted 6.38 hours per day in 1983. See the appendix for a presentation of the method for these computations.

\section{Comparison of TCM and CVM}

From the values obtained by TCM and CVM, it is apparent that differences exist. Figure 5 contains plots of the confidence intervals for the CVM estimates and sensitivity intervals for the TCM estimates. The CVM confidence interval for 1982 is $\$ 21.66$ per trip to $\$ 27.26$ per trip with a mean value of $\$ 24.46$ per trip. For the 1983 
Table 5.-TCM (1982) and CVM (1983) willingness to pay and visit estimates for big game management regions, areas, and units in Idaho.

\begin{tabular}{|c|c|c|c|c|c|c|c|c|c|c|c|c|}
\hline \multirow{4}{*}{$\begin{array}{l}\text { REGION } \\
\text { Area } \\
\text { BGMU }^{\dagger}\end{array}$} & \multicolumn{8}{|c|}{ TCM survey, 1982 season } & \multicolumn{4}{|c|}{ CVM survey, 1983 season } \\
\hline & \multicolumn{5}{|c|}{$\begin{array}{l}\text { Quallty level } \\
\text { as reported by hunters }{ }^{2}\end{array}$} & \multicolumn{3}{|c|}{$\begin{array}{l}\text { Double quallty level } \\
\text { at reported cost }\end{array}$} & \multicolumn{2}{|c|}{$\begin{array}{c}\text { Current } \\
\text { conditlons }\end{array}$} & \multicolumn{2}{|c|}{$\begin{array}{l}\text { Double } \\
\text { slghtings }\end{array}$} \\
\hline & \multirow{2}{*}{$\begin{array}{c}\text { Estlmated } \\
\text { sample } \\
\text { trips }\end{array}$} & \multicolumn{2}{|c|}{ At standard cost } & \multicolumn{2}{|c|}{ At actual cost } & \multirow{2}{*}{$\begin{array}{c}\text { Estlmated } \\
\text { sample } \\
\text { trips }\end{array}$} & \multirow[b]{2}{*}{$\begin{array}{l}\text { Total } \\
\text { WTP }\end{array}$} & \multirow{2}{*}{$\begin{array}{l}\text { WTP } \\
\text { per } \\
\text { trip }\end{array}$} & \multirow[b]{2}{*}{$\begin{array}{c}\text { Mean } \\
\text { bid }\end{array}$} & \multirow{2}{*}{$\begin{array}{c}\text { Number } \\
\text { sampled } \\
\text { and } \\
\text { usable }\end{array}$} & \multirow{2}{*}{$\begin{array}{l}\text { Mean } \\
\text { for extra } \\
\text { amount } \\
\text { bld }\end{array}$} & \multirow{2}{*}{$\begin{array}{c}\text { Number } \\
\text { sampled } \\
\text { and } \\
\text { usable }\end{array}$} \\
\hline & & $\begin{array}{l}\text { Total } \\
\text { WTP }\end{array}$ & $\begin{array}{c}\text { WTP } \\
\text { per trip }\end{array}$ & $\begin{array}{l}\text { Total } \\
\text { WTP }\end{array}$ & $\begin{array}{l}\text { WTP } \\
\text { per trip }\end{array}$ & & & & & & & \\
\hline
\end{tabular}

REGION 1

\begin{tabular}{crrrrrrrrrrrr} 
Area 1 & & & & & & & & & \\
1 & 197.03 & 11885.63 & 60.32 & 14294.36 & 72.55 & 605.82 & 45068.48 & 74.39 & 23.889 & 27 & 7.963 & 27 \\
2 & 38.63 & 2475.66 & 64.09 & 3015.80 & 78.07 & 51.45 & 4087.75 & 79.45 & 24.444 & 9 & 17.222 & 9 \\
3 & 17.50 & 782.88 & 44.74 & 915.26 & 52.30 & 23.31 & 1272.51 & 54.59 & 12.000 & 5 & 10.000 & 4 \\
5 & 9.99 & 362.78 & 36.31 & 418.69 & 41.91 & 11.39 & 503.98 & 44.25 & 2.500 & 2 & 7.500 & 2 \\
Total & 263.15 & 15506.95 & 58.93 & 18644.11 & 70.85 & 691.97 & 50932.72 & 73.61 & 21.628 & 43 & 10.119 & 42 \\
Area 2 & & & & & & & & & & & & \\
4 & 21.47 & 908.14 & 42.30 & 1059.78 & 49.36 & 33.59 & 1792.64 & 53.37 & 46.786 & 14 & 11.357 & 14 \\
6 & 28.49 & 1323.26 & 46.45 & 1561.53 & 54.81 & 43.63 & 2547.41 & 58.39 & 75.000 & 2 & 100.000 & 2 \\
7 & 5.83 & 216.87 & 37.20 & 252.32 & 43.28 & 6.65 & 299.81 & 45.08 & 21.667 & 3 & 10.000 & 3 \\
9 & 4.27 & 151.21 & 35.41 & 172.86 & 40.48 & 4.29 & 173.77 & 40.51 & - & - & - & - \\
Total & 60.06 & 2599.48 & 43.28 & 3046.49 & 50.72 & 88.16 & 4813.63 & 54.60 & 45.789 & 19 & 20.474 & 19 \\
TOTAL & 323.21 & 18106.43 & 66.02 & 21690.60 & 67.11 & 780.13 & 55746.35 & 71.46 & 29.032 & 62 & 13.344 & 61 \\
& & & & & & & & & & \\
\hline
\end{tabular}

REGION 2

\begin{tabular}{|c|c|c|c|c|c|c|c|c|c|c|c|c|}
\hline \multicolumn{13}{|l|}{ Area 1} \\
\hline 8 & 20.63 & 714.97 & 34.66 & 825.26 & 40.00 & 30.41 & 1388.48 & 45.66 & 8.125 & 8 & 4.625 & 8 \\
\hline $8 \mathrm{~A}$ & 17.73 & 698.79 & 39.41 & 824.01 & 46.48 & 23.93 & 1204.97 & 50.35 & 18.571 & 7 & 6.667 & 6 \\
\hline $9 A$ & - & - & - & - & - & - & - & - & - & - & - & - \\
\hline 10 & 1374.36 & 56657.69 & 41.23 & 63482.68 & 46.19 & 2102.82 & 97534.17 & 46.38 & 49.286 & 7 & 16.429 & 7 \\
\hline $10 \mathrm{~A}$ & 23.09 & 695.41 & 30.12 & 783.67 & 33.94 & 30.66 & 1152.63 & 37.59 & 17.000 & 5 & 3.000 & 5 \\
\hline $11 \mathrm{~A}$ & 26.52 & 972.19 & 36.66 & 1111.77 & 41.93 & 33.91 & 1501.60 & 44.28 & 31.250 & 4 & 5.000 & 4 \\
\hline 12 & 86.30 & 4116.00 & 47.70 & 4831.93 & 55.99 & 95.20 & 5398.00 & 56.70 & - & - & - & - \\
\hline 15 & 25.74 & 917.14 & 35.63 & 1058.04 & 41.11 & 34.92 & 1571.35 & 45.00 & 35.000 & 8 & 21.250 & 8 \\
\hline 16 & 6.21 & 161.77 & 26.05 & 183.22 & 29.50 & 6.74 & 200.06 & 29.68 & - & - & - & - \\
\hline Total & 1580.58 & 64833.96 & 41.08 & 73100.58 & 46.25 & 2358.59 & 109951.26 & 46.62 & 26.410 & 39 & 10.448 & 38 \\
\hline \multicolumn{13}{|l|}{ Area 2} \\
\hline 11 & 22.17 & 886.42 & 39.98 & 1015.17 & 45.79 & 27.26 & 1276.93 & 46.84 & 35.500 & 6 & 19.000 & 6 \\
\hline 13 & 4.53 & 108.54 & 23.96 & 124.84 & 27.56 & 4.92 & 135.51 & 27.54 & 100.000 & 1 & 50.000 & 1 \\
\hline 14 & 15.73 & 779.04 & 49.53 & 955.45 & 60.74 & 18.83 & 1210.13 & 64.27 & 28.750 & 4 & 5.000 & 4 \\
\hline 18 & 13.13 & 657.10 & 50.05 & 786.04 & 59.87 & 14.73 & 897.50 & 60.93 & 50.000 & 1 & 50.000 & 1 \\
\hline 19 & 8.19 & 323.08 & 39.45 & 380.84 & 46.50 & 8.46 & 393.51 & 46.51 & - & - & - & - \\
\hline Total & 63.75 & 2754.18 & 43.20 & 3262.34 & 51.17 & 74.20 & 3913.58 & 52.74 & 39.833 & 12 & 19.500 & 12 \\
\hline \multicolumn{13}{|l|}{ Area 3} \\
\hline $16 \mathrm{~A}$ & 7.78 & 280.29 & 36.03 & 320.43 & 41.19 & 7.90 & 337.14 & 42.68 & - & - & - & - \\
\hline 17 & 19.36 & 707.97 & 36.57 & 825.50 & 42.64 & 21.19 & 929.54 & 43.81 & 345.000 & 3 & 333.333 & 3 \\
\hline 20 & 20.19 & 783.91 & 38.83 & 889.75 & 44.07 & 21.38 & 966.86 & 45.22 & - & - & - & - \\
\hline Total & 47.33 & 1772.17 & 37.44 & 2035.68 & 43.01 & 50.47 & 2233.54 & 44.25 & 345.000 & 3 & 333.333 & 3 \\
\hline TOTAL & 1691.66 & 69460.31 & 41.06 & 78398.60 & 46.34 & 2483.26 & 116098.38 & 46.75 & 47.092 & 54 & 30.774 & 53 \\
\hline
\end{tabular}

REGION 3

\begin{tabular}{|c|c|c|c|c|c|c|c|c|c|c|c|c|}
\hline \multicolumn{13}{|l|}{ Area 1} \\
\hline${ }^{1} 23$ & 20.89 & 873.64 & 41.82 & 1028.37 & 49.23 & 25.43 & 1314.78 & 51.70 & - & - & - & - \\
\hline \multicolumn{13}{|l|}{ Area 2} \\
\hline $19 \mathrm{~A}$ & 16.44 & 579.66 & 35.26 & 658.48 & 40.05 & 18.73 & 760.13 & 40.58 & 0.000 & 1 & 10.000 & 1 \\
\hline 25 & 25.66 & 1057.65 & 41.22 & 1241.52 & 48.38 & 27.40 & 1363.25 & 49.75 & 11.667 & 3 & 5.000 & 2 \\
\hline Total & 42.10 & 1637.31 & 38.87 & 1900.00 & 45.13 & 46.13 & 2123.38 & 46.03 & 8.750 & 4 & 6.667 & 3 \\
\hline \multicolumn{13}{|l|}{ Area 3} \\
\hline $20 \mathrm{~A}$ & 8.84 & 367.44 & 41.57 & 431.43 & 48.80 & 9.05 & 442.01 & 48.84 & 87.500 & 4 & 60.000 & 4 \\
\hline 26 & 698.80 & 32153.84 & 46.01 & 36767.51 & 52.62 & 722.03 & 37990.25 & 52.62 & 550.000 & 2 & 12.500 & 2 \\
\hline Total & 707.61 & 32521.28 & 45.96 & 37198.94 & 52.57 & 731.08 & 38432.26 & 52.57 & 241.667 & 6 & 44.167 & 6 \\
\hline
\end{tabular}




\begin{tabular}{|c|c|c|c|c|c|c|c|c|c|c|c|c|}
\hline \multirow{3}{*}{$\begin{array}{l}\text { REGION } \\
\text { Area } \\
\text { BGMU' }\end{array}$} & \multicolumn{8}{|c|}{ TCM survey, 1982 season } & \multicolumn{4}{|c|}{ CVM survey, 1983 season } \\
\hline & \multicolumn{5}{|c|}{$\begin{array}{l}\text { Quality level } \\
\text { as reported by hunters }{ }^{2}\end{array}$} & \multicolumn{3}{|c|}{$\begin{array}{l}\text { Double quallty level } \\
\text { at reported cost }\end{array}$} & \multicolumn{2}{|c|}{$\begin{array}{c}\text { Current } \\
\text { conditions }\end{array}$} & \multicolumn{2}{|c|}{$\begin{array}{l}\text { Double } \\
\text { sightings }\end{array}$} \\
\hline & $\begin{array}{l}\text { Estlmated } \\
\text { sample } \\
\text { trips }\end{array}$ & At standard cost & 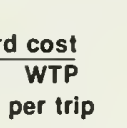 & At actual cost & $\begin{array}{l}\text { al cost } \\
\text { WTP } \\
\text { per trip }\end{array}$ & $\begin{array}{c}\text { Estimated } \\
\text { sample } \\
\text { trips }\end{array}$ & $\begin{array}{l}\text { Total } \\
\text { WTP }\end{array}$ & $\begin{array}{l}\text { WTP } \\
\text { per } \\
\text { trip }\end{array}$ & $\begin{array}{l}\text { Mean } \\
\text { bid }\end{array}$ & $\begin{array}{l}\text { Number } \\
\text { sampled } \\
\text { and } \\
\text { usable }\end{array}$ & $\begin{array}{c}\text { Mean } \\
\text { for extra } \\
\text { amount } \\
\text { bid }\end{array}$ & $\begin{array}{l}\text { Number } \\
\text { sampled } \\
\text { and } \\
\text { usable }\end{array}$ \\
\hline Area 4 & & & & & & & & & & & & \\
\hline 22 & 34.29 & 1341.77 & 39.13 & 1542.36 & 44.98 & 54.09 & 2601.04 & 48.09 & 28.571 & 7 & 7.143 & 7 \\
\hline 31 & 37.80 & 1468.25 & 38.84 & 1668.68 & 44.15 & 51.88 & 2400.27 & 46.27 & 22.500 & 8 & 7.500 & 8 \\
\hline Total & 72.09 & 2810.02 & 38.98 & 3211.04 & 44.54 & 105.97 & 5001.31 & 47.20 & 25.333 & 15 & 7.333 & 15 \\
\hline Area 5 & & & & & & & & & & & & \\
\hline 32 & 45.46 & 1789.90 & 39.37 & 2034.05 & 44.74 & 69.61 & 3267.48 & 46.94 & 58.750 & 4 & 6.250 & 4 \\
\hline $32 \mathrm{~A}$ & 30.27 & 1234.11 & 40.77 & 1412.49 & 46.66 & 47.50 & 2324.98 & 48.95 & 63.571 & 7 & 30.714 & 7 \\
\hline Total & 75.73 & 3024.01 & 39.93 & 3446.54 & 45.51 & 117.11 & 5592.46 & 47.75 & 61.818 & 11 & 21.818 & 11 \\
\hline Area 6 & & & & & & & & & & & & \\
\hline 24 & 105.77 & 5449.85 & 51.53 & 6409.03 & 60.59 & 123.22 & 7502.83 & 60.89 & 21.667 & 3 & 6.667 & 3 \\
\hline Area 7 & & & & & & & & & & & & \\
\hline 33 & 21.51 & 870.31 & 40.46 & 1003.60 & 46.66 & 27.55 & 1335.09 & 48.46 & 180.000 & 6 & 10.000 & 6 \\
\hline 34 & 5.01 & 146.55 & 29.25 & 165.24 & 32.98 & 5.22 & 172.12 & 32.97 & 15.000 & 2 & 107.500 & 2 \\
\hline 35 & 14.54 & 672.67 & 46.26 & 792.04 & 54.47 & 14.82 & 807.22 & 54.47 & - & - & - & - \\
\hline Total & 41.06 & 1689.53 & 41.15 & 960.88 & 47.76 & 47.59 & 2314.43 & 48.63 & 138.750 & 8 & 34.375 & 8 \\
\hline Area 8 & & & & & & & & & & & & \\
\hline 39 & 87.35 & 4046.70 & 46.33 & 4702.94 & 53.84 & 235.56 & 13300.91 & 56.47 & 42.857 & 21 & 24.524 & 21 \\
\hline Area 9 & & & & & & & & & & & & \\
\hline 38 & 4.86 & 330.87 & 68.08 & 409.59 & 84.28 & 4.94 & 416.27 & 84.27 & - & - & - & - \\
\hline Area 10 & & & & & & & & & & & & \\
\hline 40 & 85.97 & 3625.24 & 42.17 & 4156.52 & 48.35 & 126.64 & 6357.95 & 50.20 & 30.500 & 10 & 20.700 & 10 \\
\hline Area 11 & & & & & & & & & & & & \\
\hline 41 & 45.38 & 2293.09 & 50.53 & 2718.56 & 57.91 & 53.46 & 3254.94 & 60.89 & 79.167 & 6 & 59.167 & 6 \\
\hline 42 & 10.95 & 380.75 & 34.77 & 425.80 & 38.89 & 11.89 & 477.49 & 40.16 & 106.250 & 4 & 6.250 & 4 \\
\hline Total & 56.33 & 2673.84 & 47.47 & 3144.36 & 55.82 & 65.35 & 3732.43 & 57.11 & 90.000 & 10 & 38.000 & 10 \\
\hline TOTAL & 1299.79 & 58682.29 & 45.15 & 67568.21 & 51.98 & 1629.02 & 86089.01 & 52.85 & 66.193 & 88 & 23.356 & 87 \\
\hline $\begin{array}{c}\text { REGION } 4 \\
\text { Area } 1\end{array}$ & & & & & & & & & & & & \\
\hline 43 & 76.23 & 3289.11 & 43.15 & 3787.67 & 49.69 & 140.96 & 7282.29 & 51.66 & 32.333 & 15 & 24.667 & 15 \\
\hline Area 2 & & & & & & & & & & & & \\
\hline 44 & 8.00 & 386.25 & 48.28 & 461.70 & 57.71 & 9.68 & 578.13 & 59.72 & - & - & - & - \\
\hline Area 3 & & & & & & & & & & & & \\
\hline 48 & 87.30 & 3337.41 & 38.23 & 3736.09 & 42.80 & 167.68 & 7578.93 & 45.20 & 41.250 & 8 & 11.250 & 8 \\
\hline Area 4 & & & & & & & & & & & & \\
\hline 49 & 27.90 & 1365.02 & 48.93 & 1647.53 & 59.05 & 33.41 & 2045.76 & 61.23 & 32.500 & 2 & 10.000 & 2 \\
\hline Area 5 & & & & & & & & & & & & \\
\hline 45 & 19.65 & 976.61 & 49.70 & 1155.44 & 58.80 & 22.05 & 1286.73 & 58.36 & 75.000 & 1 & 220.000 & 1 \\
\hline 52 & 20.22 & 713.69 & 35.30 & 832.75 & 41.18 & 21.63 & 957.21 & 44.25 & 116.250 & 8 & 1.875 & 8 \\
\hline Total & 39.87 & 1690.30 & 42.40 & 1988.19 & 49.87 & 43.68 & 2243.94 & 51.37 & 111.667 & 9 & 26.111 & 9 \\
\hline Area 6 & & & & & & & & & & & & \\
\hline 53 & - & - & - & - & - & - & - & - & - & - & - & - \\
\hline Area 7 & & & & & & & & & & & & \\
\hline 46 & 18.00 & 739.42 & 41.08 & 859.97 & 47.78 & 19.37 & 937.32 & 48.39 & 43.333 & 3 & 6.667 & 3 \\
\hline Area 8 & & & & & & & & & & & & \\
\hline 47 & - & - & - & - & - & - & - & - & - & - & - & - \\
\hline 54 & 90.12 & 4536.29 & 50.34 & 5321.10 & 59.05 & 148.22 & 8916.37 & 60.16 & 26.000 & 5 & 10.000 & 5 \\
\hline 55 & 2.37 & 122.64 & 51.75 & 151.82 & 64.06 & 3.23 & 234.53 & 72.61 & 100.000 & 1 & 0.000 & 1 \\
\hline 56 & 56.86 & 2307.43 & 40.58 & 2665.56 & 46.88 & 76.26 & 3740.33 & 49.05 & 48.000 & 15 & 11.643 & 14 \\
\hline 57 & - & - & - & - & - & - & - & - & - & - & - & - \\
\hline Total & 149.35 & 6966.36 & 46.64 & 8138.48 & 54.49 & 227.71 & 12891.23 & 56.61 & 45.238 & 21 & 10.650 & 20 \\
\hline TOTAL & 406.65 & 17773.87 & 43.71 & 20619.63 & 50.71 & 642.49 & 33557.60 & 52.23 & 51.121 & 58 & 16.632 & 57 \\
\hline
\end{tabular}


TCM survey, 1982 season

CVM survey, 1983 season

\begin{tabular}{|c|c|c|c|c|c|c|c|c|c|c|}
\hline \multirow{2}{*}{$\begin{array}{l}\text { REGION } \\
\text { Area } \\
\text { BGMU }^{1}\end{array}$} & \multicolumn{3}{|c|}{$\begin{array}{l}\text { Quality level } \\
\text { as reported by hunters }{ }^{2}\end{array}$} & \multicolumn{3}{|c|}{$\begin{array}{l}\text { Double quallty level } \\
\text { at reported cost }\end{array}$} & \multicolumn{2}{|c|}{$\begin{array}{l}\text { Current } \\
\text { conditlons }\end{array}$} & \multicolumn{2}{|c|}{$\begin{array}{l}\text { Double } \\
\text { slghtings }\end{array}$} \\
\hline & $\begin{array}{l}\text { Estimated } \\
\text { sample } \\
\text { trips }\end{array}$ & 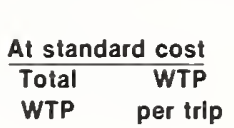 & $\begin{array}{l}\text { At actual cost } \\
\begin{array}{l}\text { Total } \\
\text { WTP }\end{array} \text { per trlp }\end{array}$ & $\begin{array}{l}\text { Estimated } \\
\text { sample } \\
\text { trips }\end{array}$ & $\begin{array}{l}\text { Total } \\
\text { WTP }\end{array}$ & $\begin{array}{l}\text { WTP } \\
\text { per } \\
\text { trip }\end{array}$ & $\begin{array}{c}\text { Mean } \\
\text { bld }\end{array}$ & $\begin{array}{c}\text { Number } \\
\text { sampled } \\
\text { and } \\
\text { usable }\end{array}$ & $\begin{array}{l}\text { Mean } \\
\text { for extra } \\
\text { amount } \\
\text { bid }\end{array}$ & $\begin{array}{c}\text { Number } \\
\text { sampled } \\
\text { and } \\
\text { usable }\end{array}$ \\
\hline
\end{tabular}

REGION 5

\begin{tabular}{|c|c|c|c|c|c|c|c|c|c|c|c|c|}
\hline \multicolumn{13}{|l|}{ Area 1} \\
\hline $\begin{array}{l}68 \\
68 \mathrm{~A}\end{array}$ & $\begin{array}{l}5.73 \\
9.77\end{array}$ & $\begin{array}{l}305.95 \\
493.44\end{array}$ & $\begin{array}{l}53.39 \\
50.51\end{array}$ & $\begin{array}{l}366.68 \\
581.65\end{array}$ & $\begin{array}{l}63.99 \\
59.53\end{array}$ & 6.11 & 391.48 & $\begin{array}{l}64.07 \\
50.52\end{array}$ & 10.000 & 2 & 0.000 & 2 \\
\hline Total & 15.50 & 799.39 & 51.57 & 948.33 & 61.18 & 15.88 & 973.13 & 61.28 & 10.000 & 2 & 0.000 & 2 \\
\hline \multicolumn{13}{|l|}{ Area 2} \\
\hline $66 \mathrm{~A}$ & 17.83 & 769.06 & 43.13 & 907.29 & 50.89 & 18.88 & 984.80 & 52.16 & 15.000 & 5 & 6.250 & 4 \\
\hline 76 & 147.55 & 6416.96 & 43.49 & 7368.42 & 49.94 & 366.39 & 19128.32 & 52.21 & 19.233 & 43 & 11.860 & 43 \\
\hline Total & 165.38 & 7186.02 & 43.45 & 8275.71 & 50.04 & 385.27 & 20113.12 & 52.21 & 18.792 & 48 & 11.383 & 47 \\
\hline \multicolumn{13}{|l|}{ Area 3} \\
\hline & 98.93 & 4778.92 & 48.31 & 5579.86 & 56.40 & 138.90 & 8031.22 & 57.82 & 16.818 & 11 & 5.909 & 11 \\
\hline 77 & 27.39 & 1700.77 & 62.09 & 2078.07 & 75.87 & 33.89 & 2628.28 & 77.55 & 49.500 & 4 & 6.250 & 4 \\
\hline 78 & 28.87 & 1466.67 & 50.80 & 1728.52 & 59.87 & 34.57 & 2093.87 & 60.57 & 2.500 & 2 & 15.000 & 2 \\
\hline Total & 155.19 & 7946.36 & 51.20 & 9386.45 & 60.48 & 207.36 & 12753.37 & 61.50 & 22.824 & 17 & 7.059 & 17 \\
\hline \multicolumn{13}{|l|}{ Area 4} \\
\hline 71 & 29.28 & 1171.95 & 40.03 & 1339.99 & 45.76 & 32.30 & 1500.91 & 46.47 & 24.000 & 10 & 21.700 & 10 \\
\hline 72 & 20.36 & 770.55 & 37.85 & 875.88 & 43.02 & 22.76 & 985.72 & 43.31 & 18.125 & 8 & 10.625 & 8 \\
\hline 74 & 25.17 & 888.74 & 35.31 & 1005.43 & 39.95 & 34.37 & 1447.45 & 42.11 & 17.667 & 15 & 14.333 & 15 \\
\hline Total & 74.81 & 2831.24 & 37.85 & 3221.30 & 43.06 & 89.43 & 3934.08 & 43.99 & 19.697 & 33 & 15.667 & 33 \\
\hline \multicolumn{13}{|l|}{ Area 5} \\
\hline 70 & 10.34 & 446.68 & 43.20 & 522.72 & 50.55 & 12.08 & 639.95 & 52.98 & 28.333 & 9 & 3.889 & 9 \\
\hline 73 & 79.39 & 3581.78 & 45.12 & 4167.41 & 52.49 & 131.96 & 7229.03 & 54.78 & 49.907 & 43 & 17.929 & 42 \\
\hline $73 \mathrm{~A}$ & 30.26 & 1310.10 & 43.29 & 1526.95 & 50.46 & 39.33 & 2074.82 & 52.75 & 25.760 & 25 & 14.600 & 25 \\
\hline Total & 119.99 & 5338.56 & 44.49 & 6217.08 & 51.81 & 183.37 & 9943.80 & 54.23 & 39.545 & 77 & 15.171 & 76 \\
\hline OTAL & 530.87 & 24101.57 & 45.40 & 28048.87 & 52.84 & 881.31 & 47717.50 & 54.14 & 28.278 & 177 & 13.286 & 175 \\
\hline
\end{tabular}

REGION 6

\begin{tabular}{|c|c|c|c|c|c|c|c|c|c|c|c|c|}
\hline \multicolumn{13}{|l|}{ Area 1} \\
\hline 21 & 13.99 & 395.56 & 28.27 & 447.70 & 32.00 & 16.08 & 564.36 & 35.10 & 95.000 & 4 & 18.750 & 4 \\
\hline $21 \mathrm{~A}$ & 19.58 & 714.57 & 36.49 & 830.40 & 42.41 & 24.67 & 1139.09 & 46.17 & 58.750 & 4 & 7.500 & 4 \\
\hline 28 & 25.52 & 1152.47 & 45.16 & 1382.28 & 54.16 & 38.33 & 2317.28 & 60.46 & 30.833 & 12 & 17.273 & 11 \\
\hline 30 & 54.79 & 2732.57 & 49.87 & 3215.81 & 58.69 & 66.89 & 3986.59 & 59.60 & 88.571 & 7 & 19.286 & 7 \\
\hline 36 & 28.38 & 1017.13 & 35.84 & 1178.41 & 41.52 & 33.88 & 1514.61 & 44.71 & 39.000 & 5 & 10.000 & 5 \\
\hline $36 \mathrm{~B}$ & 42.68 & 1501.29 & 35.27 & 1679.67 & 39.35 & 52.38 & 2126.84 & 40.60 & - & - & - & - \\
\hline Total & 184.94 & 7517.59 & 40.65 & 8734.27 & 47.23 & 232.23 & 11648.77 & 50.16 & 56.250 & 32 & 15.484 & 31 \\
\hline \multicolumn{13}{|l|}{ Area 2} \\
\hline 29 & 666.05 & 27424.36 & 41.17 & 30706.38 & 46.10 & 734.73 & 33886.26 & 46.12 & 5.000 & 2 & 0.000 & 2 \\
\hline $30 \mathrm{~A}$ & & - & - & - & - & - & - & - & 10.000 & 2 & 10.000 & 2 \\
\hline $36 \mathrm{~A}$ & 7.75 & 198.70 & 25.64 & 217.72 & 28.09 & 8.08 & 226.78 & 28.08 & - & - & - & - \\
\hline 37 & 14.06 & 512.35 & 36.44 & 586.03 & 41.68 & 15.51 & 646.46 & 41.67 & 20.000 & 4 & 0.000 & 4 \\
\hline $37 \mathrm{~A}$ & 3.13 & 87.39 & 27.93 & 103.01 & 32.93 & 3.23 & 106.44 & 32.93 & - & - & - & - \\
\hline Total & 690.99 & 28222.80 & 40.84 & 31615.14 & 45.75 & 761.55 & 34865.94 & 45.78 & 13.750 & 8 & 2.500 & 8 \\
\hline \multicolumn{13}{|l|}{ Area 3} \\
\hline 27 & 140.98 & 7044.76 & 49.97 & 8267.94 & 58.65 & 218.26 & 13060.02 & 59.84 & 100.000 & 2 & 50.000 & 2 \\
\hline \multicolumn{13}{|l|}{ Area 4} \\
\hline 50 & 42.46 & 1669.26 & 39.31 & 1931.28 & 45.48 & 59.41 & 2919.45 & 49.14 & 72.063 & 16 & 44.688 & 16 \\
\hline 51 & 35.82 & 1361.18 & 38.00 & 1564.41 & 43.67 & 45.98 & 2119.25 & 46.09 & 24.286 & 7 & 13.571 & 7 \\
\hline 58 & 15.86 & 617.92 & 38.96 & 714.64 & 45.06 & 16.43 & 740.19 & 45.05 & - & - & - & - \\
\hline 59 & 16.40 & 707.42 & 43.14 & 825.44 & 50.33 & 16.89 & 850.14 & 50.33 & 11.667 & 3 & 0.000 & 3 \\
\hline $59 \mathrm{~A}$ & 4.87 & 179.37 & 36.83 & 206.52 & 42.41 & 5.34 & 226.63 & 42.44 & 22.400 & 5 & 8.000 & 5 \\
\hline Total & 115.41 & 4535.15 & 39.30 & 5242.29 & 45.42 & 144.05 & 6855.66 & 47.59 & 47.419 & 31 & 27.419 & 31 \\
\hline \multicolumn{13}{|l|}{ Area 5} \\
\hline 60 & 39.15 & 1662.42 & 42.46 & 1925.61 & 49.19 & 40.55 & 1994.47 & 49.19 & 30.000 & 12 & 17.917 & 12 \\
\hline 61 & 40.47 & 1554.81 & 38.42 & 1761.92 & 43.54 & 50.76 & 2280.43 & 44.93 & 22.273 & 11 & 11.364 & 11 \\
\hline $62 \mathrm{~A}$ & 6.08 & 161.31 & 26.53 & 180.57 & 29.70 & 6.60 & 196.00 & 29.70 & 33.333 & 3 & 5.000 & 3 \\
\hline Total & 85.70 & 3378.54 & 39.42 & 3868.10 & 45.14 & 97.91 & 4470.90 & 45.66 & 27.115 & 26 & 13.654 & 26 \\
\hline \multicolumn{13}{|l|}{ Area 6} \\
\hline 62 & 11.88 & 427.55 & 35.99 & 487.63 & 41.05 & 12.79 & 519.06 & 40.58 & 0.000 & 2 & 2.500 & 2 \\
\hline 64 & 32.83 & 1653.87 & 50.38 & 1960.27 & 59.71 & 37.22 & 2268.20 & 60.94 & 18.889 & 9 & 17.222 & 9 \\
\hline 65 & 18.06 & 853.15 & 47.24 & 1002.45 & 55.51 & 18.36 & 1018.78 & 55.49 & 11.667 & 3 & 7.500 & 2 \\
\hline 67 & 32.77 & 1528.09 & 46.63 & 1790.99 & 54.65 & 37.98 & 2131.46 & 56.12 & 15.714 & 7 & 15.000 & 7 \\
\hline Total & 95.54 & 4462.66 & 46.71 & 5141.34 & 54.86 & 106.35 & 5937.50 & 55.83 & 15.000 & 21 & 14.000 & 20 \\
\hline
\end{tabular}


Table 5.- Continued

\begin{tabular}{|c|c|c|c|c|c|c|c|c|c|c|c|c|}
\hline \multirow{3}{*}{$\begin{array}{l}\text { REGION } \\
\text { Area } \\
\text { BGMU }\end{array}$} & \multicolumn{8}{|c|}{ TCM survey, 1982 season } & \multicolumn{4}{|c|}{ CVM survey, 1983 season } \\
\hline & \multirow[b]{2}{*}{$\begin{array}{l}\text { Estimated } \\
\text { sample } \\
\text { trips }\end{array}$} & \multicolumn{3}{|c|}{$\begin{array}{l}\text { Quality level } \\
\text { as reported by hunters }{ }^{2}\end{array}$} & $\therefore$ & \multicolumn{3}{|c|}{$\begin{array}{l}\text { Double quality level } \\
\text { at reported cost }\end{array}$} & \multicolumn{2}{|c|}{$\begin{array}{l}\text { Current } \\
\text { conditions }\end{array}$} & \multicolumn{2}{|c|}{$\begin{array}{l}\text { Double } \\
\text { sightings }\end{array}$} \\
\hline & & $\begin{array}{l}\text { At standa } \\
\text { Total } \\
\text { WTP }\end{array}$ & $\begin{array}{l}\frac{\text { d cost }}{\text { WTP }} \\
\text { per trip }\end{array}$ & $\begin{array}{l}\text { At actu } \\
\text { Total } \\
\text { WTP }\end{array}$ & $\begin{array}{l}\frac{\text { cost }}{\text { WTP }} \\
\text { per trip }\end{array}$ & $\begin{array}{c}\text { Estimated } \\
\text { sample } \\
\text { trips }\end{array}$ & $\begin{array}{l}\text { Total } \\
\text { WTP }\end{array}$ & $\begin{array}{l}\text { WTP } \\
\text { per } \\
\text { trlp }\end{array}$ & $\begin{array}{l}\text { Mean } \\
\text { bid }\end{array}$ & $\begin{array}{l}\text { Number } \\
\text { sampled } \\
\text { and } \\
\text { usable }\end{array}$ & $\begin{array}{l}\text { Mean } \\
\text { for extra } \\
\text { amount } \\
\text { bid }\end{array}$ & $\begin{array}{c}\text { Number } \\
\text { sampled } \\
\text { and } \\
\text { usable }\end{array}$ \\
\hline $\begin{array}{c}\text { Area } 7 \\
66 \\
69 \\
\text { Total }\end{array}$ & $\begin{array}{l}28.93 \\
31.25 \\
60.18\end{array}$ & $\begin{array}{l}1237.68 \\
1222.20 \\
2459.88\end{array}$ & $\begin{array}{l}42.78 \\
39.11 \\
40.88\end{array}$ & $\begin{array}{l}1431.39 \\
1394.91 \\
2826.30\end{array}$ & $\begin{array}{l}49.48 \\
44.64 \\
46.96\end{array}$ & $\begin{array}{l}35.58 \\
40.12 \\
75.70\end{array}$ & $\begin{array}{l}1794.08 \\
1856.47 \\
3650.55\end{array}$ & $\begin{array}{l}50.42 \\
46.27 \\
48.22\end{array}$ & $\begin{array}{l}11.667 \\
24.533 \\
19.708\end{array}$ & $\begin{array}{r}9 \\
15 \\
24\end{array}$ & $\begin{array}{l}4.667 \\
9.000 \\
7.375\end{array}$ & $\begin{array}{r}9 \\
15 \\
24\end{array}$ \\
\hline $\begin{array}{c}\text { Area } 8 \\
63\end{array}$ & 40.09 & 2109.99 & 52.63 & 2508.06 & 62.56 & 40.42 & 2528.40 & 62.55 & - & - & - & - \\
\hline TOTAL & 1413.80 & 59731.37 & 42.25 & 68301.44 & 48.31 & 1676.47 & 83017.74 & 49.52 & 36.236 & 140 & 16.391 & 138 \\
\hline Idaho ${ }^{4}$ & 5665.98 & 247855.84 & 43.74 & 284627.35 & 50.23 & 8092.68 & 422226.58 & 52.17 & 40.088 & 579 & 17.534 & 571 \\
\hline
\end{tabular}

\footnotetext{
${ }^{1}$ The definition of Big Game Management Units (BGMU's), in this paper termed "hunt areas" or "sites," is the same for all big game species including mule and whitetail deer. However, the grouping of these BGMU's to management areas, and the grouping of management areas into $1 D F G$ 's Administrative Regions is different for whitetail deer and for mule deer. Because whitetail deer are the dominant deer species in Regions 1 and 2, the table entries for these two Regions only follow the BGMU and Area grouping shown in the whitetail deer species management plan (Idaho Department of Fish and Game 1980a). Table entries for Regions 3-6 follow the BGMU and Area grouping shown in the mule deer species management plan (Idaho Department of Fish and Game 1980b).

${ }^{2}$ Quality level is the reported harvest of deer the year before the survey, i.e., 1981.

3 Most areas are formed by grouping two or more BGMU's. Occasionally an Area is the same as just one BGMU.

${ }^{4}$ State totals in this table may vary slightly from those in table 4 due to rounding and computing to two decimal places.
}

CVM data, the confidence interval is $\$ 32.74$ per trip to $\$ 46.79$ per trip with a mean value of $\$ 40.09$ per trip. The TCM sensitivity interval for 1982 data at standard cost is $\$ 38.88$ to $\$ 50.01$ per trip with a mean value of $\$ 43.74$ per trip. For the 1982 TCM data at reported cost, the sensitivity interval is $\$ 44.62$ to $\$ 57.44$ per trip with a mean value of $\$ 50.23$ per trip.

The TCM sensitivity interval computed with standard costs is included as a reference both for this discussion and for comparison to similar graphs in other reports of this Idaho wildlife value series. Obviously, the intervals for the 1982 CVM and TCM exhibit wide disparity contrary to the expectation that they would be much more equal. Two conditions likely account for this situation. The type of survey format for CVM may affect bid values received, and exclusion of a substitute variable in TCM regressions may cause overestimation of participation (and consequently benefits) at a given site.

Collection of the 1982 CVM data utilized a combination of open-ended and iterative survey design (see ap-

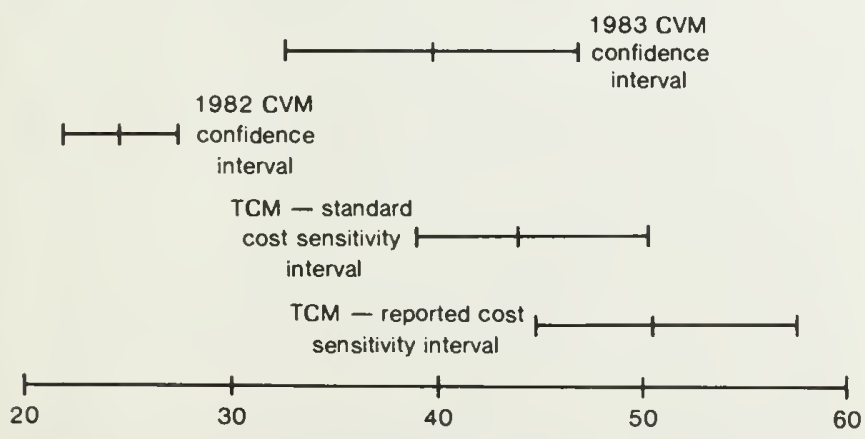

Figure 5.-Comparison of confidence intervals for CVM to sensitivity intervals for TCM. pendix). While not conclusive, some studies ${ }^{9}$ indicate use of an open-ended survey format may result in an under-estimate of maximum willingness to pay. Also, in reference to the 1982 CVM survey design, many respondents (46.65\%) indicated an infinite bid and, therefore, were not included in estimations of overall mean willingness to pay. Had these individuals been questioned further, a bid might have been elicited that could have contributed to the data entering the overall mean. The 1982 results are reported in this bulletin only for comparison and to illustrate the points made about the effects of question format on CVM studies. For any further analysis based on these results the 1983 CVM figures should be used.

When Idaho Department of Fish and Game surveyed holders of 1983 hunting licenses early in 1984, they asked several improved CVM questions designed to overcome infinite bids and open-ended bidding (see appendix). The 1983 CVM confidence interval is much closer to the sensitivity intervals for the 1982 TCM. In making this comparison, there is an implicit assumption here about the stability of purchasing power of the dollar from 1982 to 1983 and the hunter's perceptions of this purchasing power value. Also assumed is that hunters preferences are stable from 1982 to 1983 . This would result in CVM values, as applied here, slightly less than the corresponding TCM values. In addition, the 1983 CVM survey asked only about the hunter's "most recent deer hunting trip",

${ }^{9}$ Rahmatian, Morteza. 1982. Estimating the demand for environmental preservation. Unpublished Ph.D Dissertation, Department of Economics, University of Wyoming, Laramie.

Sorg, Cindy F. 1982. Valuing increments and decrements of wildlife resources: Further evidence. Unpublished M.S. Thesis, Department of Economics, University of Wyoming, Laramie. 
i.e., the hunter's last trip of the 1983 season. Because of this restriction, the possibility exists that 1983 CVM bid values are lower than if bids had been elicited for all trips. This situation is based on the concept of diminishing marginal value of the last trip taken, expecially if the last trip concluded a series of many trips.

A potentially important variable in the TCM regression analysis is a substitute site term. This variable shows the effect on a particular site value when there are other sites that could also be visited. For some activities, such as bighorn sheep hunting, there may not be substitute sites or substitute sites may be so few that their effect on value is negligible. However, in Idaho, there are many deer hunting areas available as alternatives to a particular site. Thus, not including a substitute term in the regression may result in an overestimate of value. Several substitute variables were tested but none were found significant in the regression analysis. As a result, the cost values reported from TCM may be an overestimate of willingness to pay. However, the issue of substitutes and the direction of potential bias is cloudy. (This point is discussed later.)

Given the likelihood of estimation bias in the benefits computed by each method, the CVM estimates may be regarded as a lower bound on the true but unknown value and the TCM estimate an upper bound. Moreover, the CVM and TCM values as built into this study had different purposes. The CVM values are meant to elicit information from current hunters about short-run conditions and changes. In contrast, TCM values reflect long-run conditions and changes that account for willingness to pay of not only current hunters, but also of new hunters.

One point should be stressed with regard to choosing a value from this range for decisionmaking. If a threshold value for deer hunting is identified that would change the decision under consideration, and if this value is outside the bounds identified in figure 5, then statistical variation around the actual value estimates reported here will make little difference in the decision. If the value relevant for the decision does lie in the range shown in figure 5, then further analysis is recommended to estimate the likelihood that the value of deer hunting would be within selected subintervals of the bounds. ${ }^{10}$

\section{Comparison With Other Deer Valuation Studies}

State residents who hunt with modern rifles represent the majority of deer hunters in the typical studies cited in table 6. The different time-adjusted values are not unreasonable if interpreted with recognition of the location they represent. While it is true that differences in methodology and analysis in these studies do have some

\footnotetext{
${ }^{10}$ The application of probability as a description of uncertainty in choice situations is the subject of a field called decision analysis. Two readable papers describing decision analysis are Keeney (1982) and Ulvila and Brown (1982). For in-depth reading about decision analysis, two books may be read; in order of increasing complexity, they are Brown et al. (1974) and Keeney and Raiffa (1976). These sources also contain many references to additional theoretical and applied material.
}

effect, it is also logical, for example, that deer values in Colorado are higher than in Idaho because public deer hunting opportunities in Colorado are not as widespread geographically.

Sorg and Loomis (1984), after studying not only wildlife valuation results but also results from a variety of other recreation studies, concluded that "recreation values estimated using different methods and in different locations are fairly consistent when the methodological assumptions and dates of studies are standardized." They further assert that differences in resource quality and the relative distance from user populations also contribute to variations in resource value.

\section{The Substitute Issue}

Theoretically the presence of substitute goods lowers demand for the particular good in question. The functional expression of an individual's demand curve for a good incorporates the good's own price, a relation for income, and the prices of substitute goods. As substitute goods prices rise, demand increases for the good in question, and conversely. However, no direct data were available to tell what "price" set faced each hunter in deciding where to hunt. To the degree that factors other than price, such as "quality," play a part in the decision, deer hunt areas are not the near perfect substitutes for each other that they might at first appear. Moreover, it is likely that several different products are sought under the activity collectively termed deer hunting. For example, some hunters search only for trophy bucks and may pass up many other shooting opportunities. Other rifle hunters want only an animal that likely furnishes good meat. Muzzleloaders and archery hunters look for a unique experience centered around hunting.

Such mixed results may be indicative of the conclusions reached by Hendee (1974), who discussed the inadequacy of traditional concepts of quality such as "game-bagged" and "days-afield." Hendee goes on to propose a multiple satisfaction approach based on experiences. The conclusion from these mixed results may be that quality is currently a more complex concept than traditionally acknowledged.

Some issues involved in the effect of spatial location on substitute terms in TCM regressions are discussed by Caulkins et al. (1985). They show that if a substitute term is, in fact, relevant in the analysis, then the sign of the cross price term (positive or negative) and the sign of the correlation between the goods own price and the alternative good price (positive or negative) result in four possible cases. Their argument is that it is indeed possible for the presence of an alternative site to contribute positively to benefits associated with a site under analysis.

In terms of the Idaho deer study, all the substitute index terms contributed positively to the regressions for trips per capita. Prior to access to the Caulkins et al. (1985) paper, this was considered an anomaly in the data. In retrospect, these results may be an expression of the spatial pattern of deer hunter origins with respect to deer hunting areas. 
Table 6. - Values per Wildlife and Fish User Day (WFUD) from this study compared with selected other studies.

\begin{tabular}{|c|c|c|c|}
\hline $\begin{array}{l}\text { Reference and } \\
\text { location }\end{array}$ & TCM & CVM & Comments \\
\hline $\begin{array}{l}\text { Miller (1980) } \\
\text { Colorado }\end{array}$ & $\begin{array}{c}65.23 \\
{ }^{2}(114.61)\end{array}$ & $\begin{array}{c}9.11 \\
(16.00)\end{array}$ & $\begin{array}{l}\text { TCM values adjusted for travel time but not for } \\
\text { substitutes; CVM represents additional WTP } \\
\text { to get to hunt site, but not WTP at the hunt } \\
\text { site. }\end{array}$ \\
\hline $\begin{array}{l}\text { Martin et al. } \\
\text { (1974) Arizona }\end{array}$ & $\begin{array}{c}18.54 \\
(40.91)\end{array}$ & - & $\begin{array}{l}\text { Individual observation TCM with allowance for } \\
\text { travel time and substitutes. }\end{array}$ \\
\hline $\begin{array}{l}\text { Hansen }(1977)^{3} \\
\text { Intermountain }\end{array}$ & - & $\begin{array}{c}20.55 \\
(33.03)\end{array}$ & Mail survey, noniterative and open-ended. \\
\hline $\begin{array}{l}\text { Wennergren et al. } \\
\text { (1973) Utah }\end{array}$ & $\begin{array}{r}9.34 \\
(20.61) \\
{ }^{4}(26.79)\end{array}$ & & $\begin{array}{l}\text { Zonal TCM; no adjustment for travel time or } \\
\text { substitutes. }\end{array}$ \\
\hline $\begin{array}{l}\text { This study } \\
\text { Idaho }\end{array}$ & $\$ 48.99$ & 36.08 & $\begin{array}{l}\text { TCM travel time adjustments but no substi- } \\
\text { tutes (1982); CVM (1983) }\end{array}$ \\
\hline \multicolumn{4}{|c|}{$\begin{array}{l}{ }^{1} \text { The information for this table was taken from Sorg and Loomis (1984):5-7. The studies here } \\
\text { vere chosen on the basis of similar methodology. } \\
2 \text { Values obtained in the study are reported first. The figures in parentheses show values after } \\
\text { diustment for inflation using implicit price deflator indexes such as those found in the Statistical } \\
\text { bstract of the United States. } \\
{ }^{3} \text { Unpublished report by Christopher Hansen. A report on the value of wildlife. } 23 \text { p. USDA } \\
\text { orest Service, Intermountain Region, Dec. 1, 1977. Ogden, Utah. } \\
{ }^{4} \text { This value has also been adjusted to reflect typical travel time. }\end{array}$} \\
\hline
\end{tabular}

\section{CONCLUSIONS AND RECOMMENDATIONS}

A Regional Travel Cost Model was for the most part successful in deriving recreational values for deer hunting in Idaho using data collected by the Idaho Department of Fish and Game. The per capita (stage I) demand curve included statistically significant variables on distance, income, and site quality. However, no tested measure of substitute sites was found significant. If competitive substitute relationships between hunt areas are truly present, but are not reflected in these data, then dollar values derived using TCM are likely an overestimate of actual willingness to pay. The degree of overestimation is not known. Dollar values derived from TCM were $\$ 50.23$ per trip using respondents' actual reported travel costs.

The TCM values using reported actual transport cost are probably more accurate in the case of deer hunting than a standard transport cost based on suburban driving in a mid-size car. In the case of deer hunting, pickup trucks on dirt roads may be more typical.

Because the 1982 CVM phone survey applied an openended bidding procedure, the combined effect of bidding technique and infinite bids $(46.65 \%$ of respondents) for deer hunting may have resulted in an underestimate of actual willingness to pay. The degree of underestimation is not known. The average value of a trip was $\$ 24.46$. Adjustments for overestimation of TCM and underestimation of CVM bring the values closer together. Subsequently, data gathered in 1983 for CVM analysis indicated willingness to pay ( $\$ 40.09$ per trip) closer to 1982 TCM values because some problems in the earlier 1982 CVM survey were corrected.
Calculation of mean net willingness to pay from CVM is generally straightforward and requires only a few days' work. These features makes CVM attractive as a methodology for rapid valuation of wildlife benefits. In addition, the ability to value all wildlife use, changes in use, and both primary and nonprimary use is another asset of CVM. In this study the particular issue addressed by CVM questions was the short-term willingness to pay by current users.

Both TCM and the 1982 CVM survey are based on the entire hunting season. The 1983 CVM survey was based on the last trip. It should be noted that the CVM surveys apply to current hunters and so the results are considered short run when considering changed conditions. Conversely, the TCM approach for changed conditions reflects a longer range outlook. The mean CVM bid and its corresponding confidence interval may be compared to the TCM trip value estimate and its sensitivity interval.

The advantage of CVM is the ease of data analysis for calculating mean willingness to pay. Its main disadvantage is its reliance on the survey format in which questionnaire design is crucial. Further, in order to derive predictive bid curves and make statistical comparisons across groups, it is necessary to have specific information about respondents, such as income, age, and hunting preferences.

The primary advantage of TCM is that it is based on actual behavior rather than hypothetical situations posed to respondents. The disadvantages relate to selection of the value of travel time and the need for extensive data analysis. With TCM, as applied in this study, one advantage is the ability to estimate, through use of site-specific variables such as quality, how number of trips would change if the number of deer harvested changed. 
Perhaps the biggest practical disadvantage to TCM is the time it takes to construct a Regional Travel Cost Model. Data aggregation, computing additional variables, and selecting variables for regression is time consuming. Once a statistically significant regression is found, calculation of a second stage demand curve and sensitivity intervals involves some additional work. And, if specialized computer programs have to be planned and written, these latter steps could also take significant time. In this deer study, data analysis took about 1 month with analyst and technician working about half time. Specialized computer programs for the most part were available from other work completed on the overall Idaho study. Following data analysis, further analysis and iterative re-analysis took another month.

By contrast, the CVM analysis of mean willingness to pay took only 2 or 3 days. Further analysis took almost a month. Thus, if a survey must be performed to collect data for valuation, CVM is faster in terms of data compilation and statistical analysis. Also, the CVM survey instrument could be designed to elicit responses more appropriate to long-run changes if that were desired. However, if origin-destination data already exist in the form of permits or license plate numbers, etc., then TCM might be more cost-effective in valuing recreation activities.

Certain types of information will help sort out substitute issues in future studies in Idaho or other states. Surveys for TCM should be designed to find out why participants chose the site they visited, if they considered any other sites, and why they chose not to go to the other sites considered. It would also help to know the extent of knowledge participants have about various sites so that some inferences may be made about the choice set available and the degree to which assumptions hold about perfect information. In order to determine an efficient survey instrument, just these items should be pretested before incorporation in a major survey effort. Some research will be required to find out if the questions should be open-ended and any answer considered, or if they should offer classes of motives and the respondent asked to fit his situation within such classes.

To help focus either TCM or CVM efforts, those considering surveys should define, formally and rigorously, the most important and obvious uses for the numerical results of the study. Sponsors of the study should work with the study researchers to determine the extent of uncertainty in the results and the degree to which uncertainty will affect the decisions and uses that will be based on the study results. In turn, these determinations will affect the survey method, its content, and the method of analysis.

Both TCM and CVM surveys should be combined and conducted concurrently, as was done in this study, with TCM and CVM information asked of the same individual wherever possible. This concurrent survey, in addition to the regular valuation objectives of a study, would allow comparison and validation for the results.

Some inoffensive method of determining individual income on a confidential basis would be very helpful in economic analysis. Perhaps asking for income within classes would suffice. These data would cover wage or salary income plus income from other sources. This information will help to better analyze and explain the income-related effect on demand for deer hunting.

This study serves primarily to estimate the value of the deer hunting experience in Idaho. In addition, this study illustrates the TCM and CVM approaches to valuation of specific nonmarketed products of wildland management. Judgment cannot be made whether the TCM value is better than the CVM value, all else being equal. Neither method is superior in all cases, and both have certain advantages and disadvantages depending on the resources available in a specific situation.

\section{LITERATURE CITED}

Bishop, Richard C., and Thomas A. Heberlein. 1979. Measuring values of extramarket good: Are indirect measures biased? American Journal of Agricultural Economics 61(5):926-930.

Bowes, Michael D., and John B. Loomis. 1980. A note on the use of travel cost models with unequal zonal populations. Land Economics 56(4):465-470.

Box, G. C. P., and D. R. Cox. 1964. An analysis of transformations. Journal of the Royal Statistical Society (Series B) 26(2):211-243.

Brookshire, David S., Mark A. Thayer, William D. Schulze, and Ralph C. d'Arge. 1982. Valuing public goods: A comparison of survey and hedonic approaches. American Economic Review 72(1):165-177.

Brown, Rex V., Andrew S. Kahr, and Cameron Peterson. 1974. Decision analysis for the manager. 618 p. Holt, Rinehart and Winston, New York, N.Y.

Brown, William, Colin Sorhus, Bi-lian Chou-Yang, and Jack Richards. 1983. Using individual observations to estimate recreation demand functions: A caution. American Journal of Agricultural Economics 65(1): 154-157.

Caulkins, Peter P., Richard C. Bishop, and Nicolaas W. Bouwes, Sr. 1975. Omitted cross-price variables biases in the linear travel cost model: Correcting common misperceptions. Land Economics 61(2):182-187.

Cesario, Frank, and Jack Knetsch. 1970. Time bias in recreation benefit estimates. Water Resources Research 6(3):700-705.

Cesario, Frank. 1976. Value of time in recreation benefit studies. Land Economics 52(1):32-40.

Clawson, Marion, and Jack Knetsch. 1966. Economics of outdoor recreation. 327 p. The Johns Hopkins University Press, Baltimore, Md.

Driver, B. L. 1985. Specifying what is produced by management of wildlife by public agencies. Leisure Sciences 7(3):281-295.

Dwyer, John, John Kelly, and Michael Bowes. 1977. Improved procedures for valuation of the contribution of recreation to national economic development. Water Resources Center Report No. 128. University of Illinois at Urbana, Champaign.

Gwynn, Dwight E., and John L. Schmidt. 1984. Managing deer hunters on private lands in Colorado. The Wildlife Society Bulletin 12(1):12-19. 
Haspel, Abraham E., and F. Reed Johnson. 1982. Multiple destination trip bias in recreation benefit estimation. Land Economics 58(3):364-372.

Hendee, John C. 1974. A multiple-satisfaction approach to game management. The Wildlife Society Bulletin 2(3):104-113.

Idaho Department of Fish and Game. 1980a. Whitetail deer species management plan 1981-1985. 38 p. Boise.

Idaho Department of Fish and Game. 1980b. Mule deer species management plan 1981-1985. 120 p. Boise.

Just, Richard E., Darrell L. Hueth, and Andrew Schmitz. 1982. Applied welfare economics and public policy. 491 p. Prentice-Hall, Englewood Cliffs, N.J.

Keeney, Ralph L., and Howard Raiffa. 1976. Decisions with multiple objectives: Preferences and value tradeoffs. 569 p. John Wiley and Sons, New York, N.Y.

Keeney, Ralph L. 1982. Decision analysis: An overview. Operations Research 30(5):803-838.

Knetsch, Jack, and Robert K. Davis. 1966. Comparisons of methods for recreation evaluation. p. 125-142. In Water Research. 526 p. The John Hopkins Press, Baltimore, Md.

Martin, William, Russel Gum, and Arthur Smith. 1974. The demand for and value of hunting, fishing, and general rural outdoor recreation in Arizona. Technical Bulletin 211. The Agricultural Experiment Station, University of Arizona, Tucson.

Miller, Ronald R., Anthony A. Prato, and Robert A. Young. 1977. Congestion, success and the value of Colorado deer hunting experiences. p. 129-136. In Transactions of the 42nd North American wildlife and natural resources conference. Kenneth Sabol, editor. 523 p. Wildlife Management Institute, Washington, D.C.

Miller, Ronald. 1980. The demand for the Colorado deer hunting experience. Ph.D. dissertation, 161 p. Department of Economics, Colorado State University, Fort Collins.

Mumy, Gene E., and Steve H. Hanke. 1975. Public investment criteria for underpriced public products. American Economic Review 65(4):712-720.

Randall, Alan, and John R. Stoll. 1983. Existence value in a total valuation framework. p. 265-274. In Managing air quality and scenic resources at national parks and wilderness areas. Robert D. Rowe and Lauraine G. Chestnut, editors. 314 p. Westview Press, Boulder, Colo.
Rao, Potluri, and Roger Leroy Miller. 1971. Some ad hoc procedures in regression analysis. In Applied Econometrics. 235 p. Wadsworth Publishing Company, Belmont, Calif.

Rosenthal, Donald H., John B. Loomis, and George L. Peterson. 1984. The travel cost model: Concepts and applications. USDA Forest Service General Technical Report RM-109, 10 p. Rocky Mountain Forest and Range Experiment Station, Fort Collins, Colo.

Sorg, Cindy F., and John B. Loomis. 1984. Empirical estimates of amenity forest values: A comparative review. USDA Forest Service General Technical Report RM-107, 23 p. Rocky Mountain Forest and Range Experiment Station, Fort Collins, Colo.

Strong, Elizabeth. 1983. A note on the functional form of travel cost models with unequal populations. Land Economics 59(3):342-349.

Ulvila, Jacob W., and Rex V. Brown. 1982. Decision analysis comes of age. Harvard Business Review 60(5):130-141.

U.S. Department of Transportation. 1982. Cost of owning and operating automobiles and vans. 20 p. Federal Highway Administration, Office of Highway Planning, Highway Statistics Division.

U.S. Water Resources Council. 1979. Procedures for evaluation of National Economic Development (NED) benefits and costs in water resources planning. Federal Register. December 14. 44(243):72892-72976.

U.S. Water Resources Council. 1983. Economic and environmental principles for water and related land resources implementation studies. 137 p. U.S. Government Printing Office, Washington, D.C.

Vaughn, William J., and Clifford S. Russell. 1982. Valuing a fishing day: An application of a systematic varying parameter model. Land Economics 58(4):450-463.

Walsh, Richard. 1983. Recreation economics decisions. 524 p. Citizen Printing Co., Fort Collins, Colo.

Wennergren, Boyd, Herbert Fullerton, and Jim Wrigley. 1973. Estimation of quality and location values for resident deer hunting in Utah. Utah Agricultural Experiment Station, Bulletin 448, 24 p. Utah State University, Logan.

Wilman, Elizabeth. 1980. The value of time in recreation benefit studies. Journal of Environmental Economics and Management 7(3):272-286.

Ziemer, Rod F., Wesley N. Musser, and R. Carter Hill. 1980. Recreation demand equations: Functional form and consumer surplus. American Journal of Agricultural Economics 62(1):136-141. 


\section{APPENDIX}

\section{Average and Marginal Consumer Surplus- Conditions of Equality}

The objective of the proof is to show that average benefits are equal to marginal benefits in relation to the per capita (stage I) demand curve. The means to accomplish this is to derive the mathematical expression for the benefits in each case and to show these are equal. The conditions under which this is true are:

1. Demand relationships between visits per capita and price (cost of travel) can be validly modeled with an exponential functional form such as

or equivalently,

$$
\ln (q)=a-b p
$$

$$
\mathrm{q}=\mathrm{e}^{\mathrm{a}-\mathrm{bp}}
$$

where q is quantity, in this case, visits per capita $p$ is price, in this case, travel cost

a is the intercept parameter

$\mathrm{b}$ is the slope parameter

2. The only shifting variables allowed in the equation affect the intercept. No slope shifting variables are in the equation.

3. A slight relaxation of condition 2 occurs if there are slope shifting variables but they do not change from the "before" to the "after" states.

4. Each origin is a price taker in that people from that origin may visit the site as many times as they desire at their current travel cost. Therefore, the supply curve facing a given origin is horizontal. Due to differences in location from the site, each origin faces a different horizontal supply curve.

\section{The "Before" State}

Figure A1 shows the overall scope of the changes considered in the proof. At equilibrium in state 1, i.e., the "before" state, the demand curve has a quantity intercept of $\mathrm{e}^{\mathrm{a}_{1}}$ when price is zero. As price increases, quantity decreases and asymptotically approaches zero for very large $\mathrm{p}$. For a price of $\mathrm{p}_{1}$, visits per capita to a site from a specific origin are $\mathrm{q}_{1}$.

Total benefits per capita that accrue to the presence of the site, given all other existing sites, are represented by the shaded area labeled CS 1 (consumer surplus in state 1). This area is found by integrating under the demand curve and above the price line $\mathrm{p}_{1}$.

To perform this integration, let a small segment of the area, dCS, be

as shown in figure A1.

$$
\mathrm{dCS}=\mathrm{qdp}
$$

Then

$$
\mathrm{CS}=\int \mathrm{dCS}=\cdot \int_{\mathrm{p}_{1}}^{\mathrm{p}} \mathrm{q} \mathrm{dp}
$$

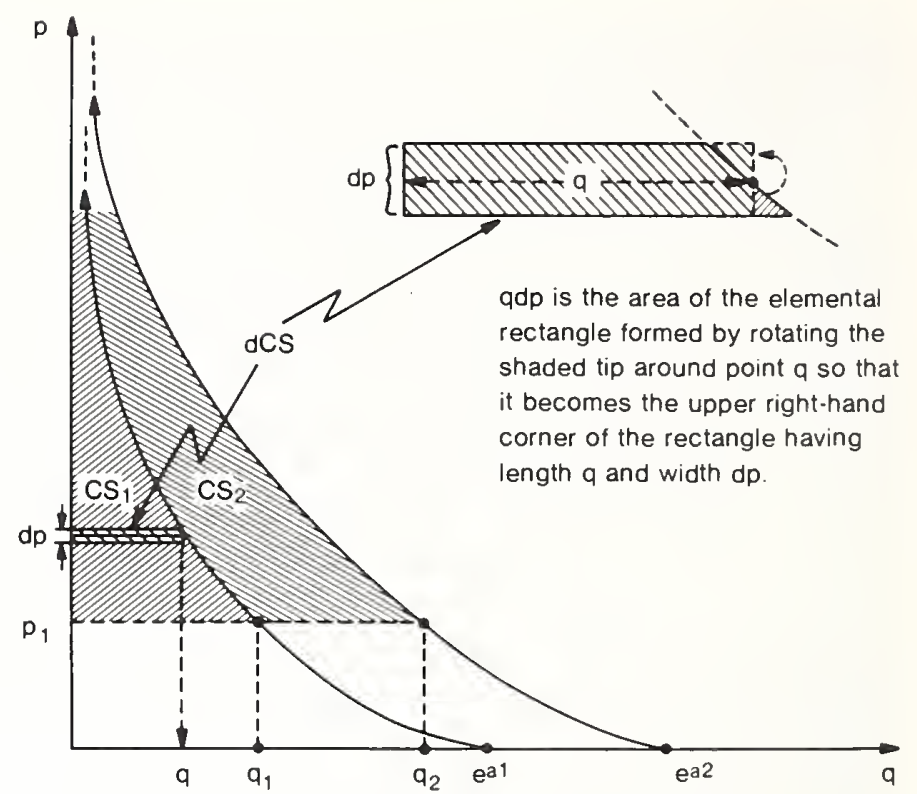

Figure A1. - Changes in consumer surplus based on exponential (semi-log, dependent variable) demand curves.

The limits of integration define the lower boundary of the CS area, the $\mathrm{p}_{1}$ price line, and the upper boundary of the CS area, the point where p goes to infinity and q goes to zero. In spite of these extreme values, it turns out the CS area is finite.

Substitute for $q$ from equation [A2] in the integral in equation [A4] giving

$$
\mathrm{CS}_{1}=\int_{\mathrm{p}_{1}}^{\mathrm{p}} \mathrm{e}^{\mathrm{a}_{1}-\mathrm{b}_{1} \mathrm{p}} \mathrm{dp}
$$

where the subscript 1 denotes state one ("'before"). Continuing with the integration gives

$$
\left.\mathrm{CS}_{1}=\mathrm{e}^{\mathrm{a}_{1}} \int_{\mathrm{p}_{1}}^{\mathrm{p}_{1}} \mathrm{e}^{-\mathrm{b}_{1} \mathrm{p}} \mathrm{dp}=-\frac{1}{b_{1}} \mathrm{e}^{\mathrm{a}_{1}-b_{1} p}\right]_{p_{1}}^{p}
$$

Evaluating the expression in [A6] at the limits of integration gives

$$
\begin{gathered}
C S_{1}=\left(-\frac{1}{b_{1}} e^{a_{1}-b_{1} p}\right)-\left(-\frac{1}{b_{1}} e^{a_{1}-b_{1} p_{1}}\right) \\
C S_{1}=\frac{1}{b_{1}}\left(e^{a_{1}-b_{1} p_{1}}-e^{a_{1}-b_{1} p}\right)
\end{gathered}
$$

In order to include the entire area under the demand curve, let $p$ (not $p_{1}$ ) become infinitely large, $(\rightarrow \infty)$. For large $p$

$$
\mathrm{e}^{\mathrm{a}_{1}-\mathrm{b}_{1} \mathrm{p}}=\mathrm{q} \rightarrow 0
$$

so that the expression for CS in [A8] becomes

$$
\mathrm{CS}_{1}=\frac{1}{\mathrm{~b}_{1}}\left(\mathrm{e}^{\mathrm{a}_{1}-\mathrm{b}_{1} \mathrm{p}_{1}}\right)=\frac{\mathrm{q}_{1}}{\mathrm{~b}_{1}}
$$


Average consumer surplus in state one per trip made $\left(\mathrm{q}_{1}\right)$ is

$$
\overline{\mathrm{CS}}_{1}=\frac{\mathrm{CS}_{1}}{\mathrm{q}_{1}}=\frac{1}{\mathrm{~b}_{1}}\left(\mathrm{e}^{\mathrm{a}_{1}-\mathrm{b}_{1} \mathrm{p}_{1}}\right) \frac{1}{\mathrm{q}_{1}}
$$

$$
\begin{aligned}
& \text { But } \quad \mathrm{e}^{\mathrm{a}_{1}-\mathrm{b}_{1} \mathrm{p}_{1}} \text { is } \mathrm{q}_{1} \text {, so } \\
& \overline{\mathrm{CS}}_{1}=\frac{1}{\mathrm{~b}_{1}}
\end{aligned}
$$

Thus, average consumer surplus per trip in state one, the "before" state, is simply the inverse of the slope parameter from the demand equation, assuming the conditions previously stated are met.

\section{The "After" State}

Now assume that managers of the recreational sites under consideration wish to increase the attractiveness of the specific site, for example, by increasing the number of animals or fish potentially harvestable. This new condition becomes the "after" state.

The new attractiveness at the site increases the intercept to $\mathrm{e}^{\mathrm{a}_{2}}$, but does not affect the slope coefficient $b$, as we have assumed, so $b_{1}=b_{2}=b$, (i.e., quality is an intercept shifter only). Using the result of the previous section, that, in general under the stated conditions,

$$
\operatorname{CS}=\frac{1}{b} \quad\left(e^{a-b p}\right)=\frac{q}{b}
$$

and placing the subscript (2) for the "after" state on the variables, total per capita consumer surplus for the "after" state is

$$
\mathrm{CS}_{2}=\frac{1}{\mathrm{~b}_{2}}\left(\mathrm{e}^{\mathrm{a}_{2}-\mathrm{b}_{2} \mathrm{p}}\right)=\frac{\mathrm{q}_{2}}{\mathrm{~b}_{2}}
$$

Note that "after" average CS is also $\frac{1}{b_{2}}=\frac{1}{b}$ :

The total change in consumer surplus from the "before" to the "after" state is

$$
\begin{aligned}
\Delta \mathrm{CS} & =\mathrm{CS}_{2}-\mathrm{CS}_{1} \\
\Delta \mathrm{CS} & =\frac{\mathrm{q}_{1}}{\mathrm{~b}_{2}}-\frac{\mathrm{q}_{2}}{\mathrm{~b}_{1}}
\end{aligned}
$$

But, as noted, $b_{1}=b_{2}=b$, so

$$
\Delta \mathrm{CS}=\frac{\mathrm{q}_{2}-\mathrm{q}_{1}}{\mathrm{~b}}
$$

The marginal change per unit increase in trips is defined as

$$
\begin{aligned}
& \frac{\Delta \mathrm{CS}}{\Delta \mathrm{q}}=\frac{\frac{\mathrm{q}_{2}-\mathrm{q}_{1}}{\mathrm{~b}}}{\mathrm{q}_{2}-\mathrm{q}_{1}} \\
& \frac{\Delta \mathrm{CS}}{\Delta \mathrm{q}}=\frac{1}{\mathrm{~b}}
\end{aligned}
$$

And since $b=b_{1}=b_{2}$, combine the results of the derivation of "before" average consumer surplus and the derivation of the marginal consumer surplus caused by the change to the "after" state.

Thus,

$$
\overline{\mathrm{CS}}_{1}=\frac{1}{\mathrm{~b}}=\frac{\Delta \mathrm{CS}}{\Delta \mathrm{q}}=\mathrm{CS}_{\operatorname{marg}}=\overline{\mathrm{CS}}_{2}
$$

and the proof is complete given that the preceding conditions are met.

Note in the proof that the relationship in equation [A20] does not depend on the price level even though figure A1 shows price unchanging. Neither do the key equations for "before" and "after" consumer surplus, equation [A10] and [A14], respectively. Under the stated conditions, there may or may not be a price change along with the demand curve shift. Regardless, it does not affect the equality between the "before" average consumer surplus and the "before" - to - "after" marginal change in consumer surplus. Moreover, the price may change in either direction without affecting the results. In addition, the same analysis for marginal and average changes along a single stationary exponential demand curve also shows that average consumer surplus is the same as marginal consumer surplus. 
The survey of deer hunters in Idaho was originated, developed, and administered by personnel from the Idaho Department of Fish and Game and the University of Idaho cooperative Wildlife Unit. To make available as much information as possible about this study, the survey instruments are reproduced here with permission of the Idaho Department of Fish and Game.

\section{Big Game Survey}

Tag Type

Tag No.

Continue if this person did hunt in 1982

In addition to getting hunter success, the Department and the University of Idaho are asking a sample of hunters to answer questions to help determine the value of Idaho's deer resource.

Can you please tell me how many deer hunting trips you made and to what units in 1982 ?

Counting yourself, No. people in your

Unit No.

Drainage or general area vehicle with tags.

1.

2.

3.

Now, I would like some specific information about each trip:

(Ask separately about each trip even if to some area more than once).

Did you visit more than one unit on your trip (or 1st, 2 nd, 3rd trip) to unit units (list)

Did you drive the entire distance to where you went hunting in unit trip

If no, what different type of transportation did you use?

car

small plane

airline

horses

jet boat

back pack

other

How many days did you hunt on this trip to unit (to nearest $1 / 2$ day) and average number of hours spent hunting per day

Now, please estimate the total amount you spent on this trip for:

Transportation

Food

Motel-hotel

Guide Services

Do you feel this trip to unit was worth more than you actually spent $?$

If no, stop; if yes, go on.

One final question about this trip:

The cost of everything is increasing. How much would the trip cost have to rise above what you spent this year before you would not hunt in unit again? \$

Ask in terms of percentage - 10, 20, etc. 
In addition to getting hunter success, the Department and the University of Idaho are asking a sample of hunters to answer questions to help determine the value of Idaho's deer.

Indicate combined deer/elk hunts in the species designation:

$$
\begin{aligned}
& \text { Separate trips: } \text { deer }=1 \quad \text { Combined trips: } \text { deer }=91 \\
& \begin{array}{lll}
\text { elk }=2 & \text { elk }=92
\end{array}
\end{aligned}
$$

I WOULD LIKE TO ASK YOU SOME QUESTIONS ABOUT YOUR MOST RECENT DEER (OR ELK) HUNTING TRIP. WHAT AREA DID YOU VISIT ON YOUR MOST RECENT TRIP? . (Record unit but talk about the area mentioned).

WAS THE PRIMARY PURPOSE OF YOUR TRIP TO general area HUNT DEER (OR ELK)?

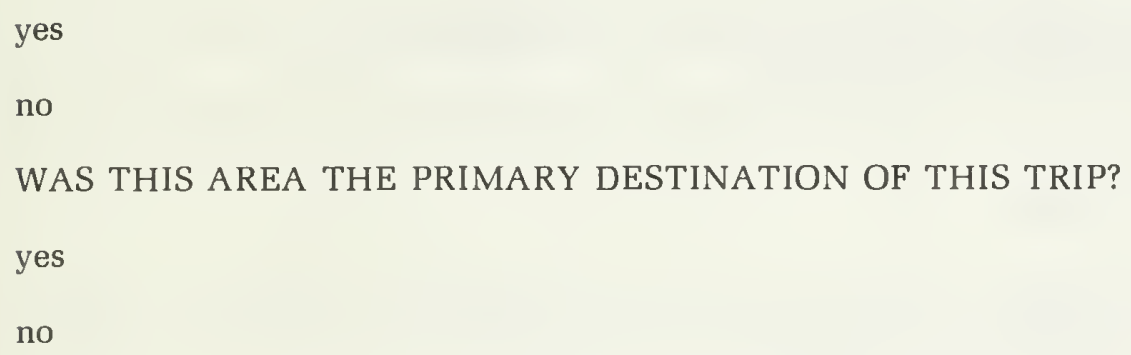
hours

THE NEXT FEW QUESTIONS CONCERN THE AMOUNT OF MONEY THAT WAS YOUR SHARE OF THE AMOUNT SPENT ON THIS TRIP.

PLEASE ESTIMATE THE AMOUNT SPENT ON TRANSPORTATION ON THIS TRIP $\$$

NOW, ESTIMATE THE AMOUNT SPENT ON ACCOMMODATIONS ON THIS TRIP $\$$

WAS THIS TRIP TO general area WORTH MORE THAN YOU ACTUALLY SPENT?

no stop here

yes - NEXT, I WOULD LIKE TO ASK SOME HYPOTHETICAL QUESTIONS ABOUT THIS TRIP TO general area . ASSUME THAT THE TRIP BECAME MORE EXPENSIVE, PERHAPS DUE TO INCREASED TRAVEL COSTS OR SOMETHING, BUT THE GENERAL DEER (OR ELK) HUNTING CONDITIONS WERE UNCHANGED. YOU INDICATED THAT \$ WERE SPENT ON THIS TRIP FOR YOUR INDIVIDUAL USE.

WOULD YOU PAY \$ MORE THAN YOUR CURRENT COST RATHER THAN NOT BE ABLE TO HUNT DEER (OR ELK) AT THIS AREA?

Protest - will not answer 
Record why?

1. it's my right

2. my taxes already pay for it

3 no extra value

4. like to, but not able

5. refuse to put a dollar value

3. yes

no Work between 0 and $20 \%$ to find highest acceptable value. Split the difference in half until you reach nearest $\$ 1$ (less than $\$ 10$ ) or nearest $\$ 5$ (greater than $\$ 10$ )

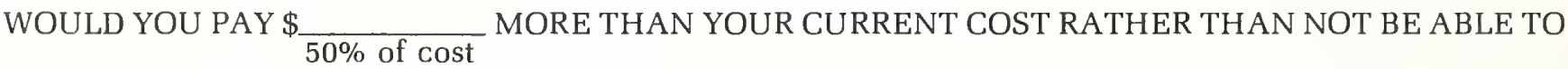
HUNT DEER (OR ELK) AT THIS AREA?

yes

no Work between 20 and $50 \%$ to find highest acceptable value. Split the difference in half until you reach nearest $\$ 1$ (less than $\$ 10$ ) or nearest $\$ 5$ (greater than $\$ 10$ )

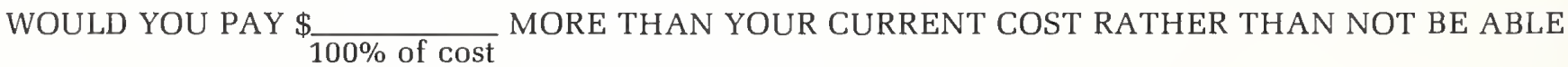

TO HUNT DEER (OR ELK) AT THIS AREA?

yes

no Work between 50 and $100 \%$ to find highest acceptable value. Split the difference in half until you reach nearest $\$ 1$ (less than $\$ 10$ ) or nearest $\$ 5$ (greater than $\$ 10$ ).

Keep going until you receive a negative answer. Use 100\% increments.

Work between last two bids to find highest acceptable value.

After last big

IS THIS AMOUNT \$ bid WHAT YOU PERSONALLY WOULD PAY, NOT FOR ALL MEMBERS OF YOUR PARTY?

no Repeat bids for personal value

yes - HOW MANY DEER (OR ELK) PER DAY DID YOU SEE ON THIS TRIP?

number

NOW, SUPPOSE THAT INSTEAD OF $\#$ times DEER (OR ELK) YOU COULD HAVE SEEN

HOW MUCH, IF ANY, WOULD YOU INCREASE YOUR VALUE OF \$ double \# $\$$

THAT IS ALL THE QUESTIONS I HAVE FOR YOU. THANK YOU FOR TAKING THE TIME TO ANSWER THESE QUESTIONS. YOUR RESPONSES WILL BE VERY VALUABLE TO US.

GOOD-BYE. 


\section{Computation of Benefit Value per Wildlife and Fish User Day (WFUD)}

Calculation method:

$$
\$ / \text { trip } \div \text { days hunting/trip }=\ldots \text { _ } \$ \text { day hunting }
$$

(X)

12 hours hunting/WFUD $\div \mathrm{hr}$ hunting/day hunting $=$ day hunting/WFUD

$=\longleftarrow$ \$WFUD

Example (for overall actual cost line of table 4):

$\$ 50.23 /$ trip $\div 1.87$ days hunting/trip $=\$ 26.8610 /$ day hunting

(from table 4) (from table 1)

$12 \mathrm{hrs}$ hunting/WFUD $\div 6.58 \mathrm{hrs}$ hunting/day hunting $=1.8237$ days hunting/WFUD

(by definition) (from table 1)

$=\$ 48.9866 /$ WFUD

(or rounded to two decimal places $=\$ 48.99 /$ WFUD as in table 4)

\section{Computation of Cost of Travel}

As stated in the section on calculation of TCM benefits, the total unit cost of travel in dollars per person per mile is composed of two parts. One is the persons share of the cost of the vehicle operation; the other is the assumed deterrent effect of travel time, as estimated in money terms, that accrues as trip length increases.

The per-person share of vehicle operating cost is computed as the quotient

$$
\frac{\text { TCPM }}{\text { NPIP }}=\text { PPVC }
$$

where TCPM = vehicle travel cost per mile

NPIP = number of people in the party

PPVC = per person share of vehicle cost.

The variable TCPM is standard cost (i.e., $\$ 0.135 / \mathrm{mile}$ ), overall actual cost $(\$ 0.183 / \mathrm{mile})$, or resident rifle hunter actual cost ( $\$ 0.218 /$ mile), depending on the category of hunter. The overall average for number of people in the party is 2.54 (reported in table 1 as number of people per vehicle). However, this overall value was not used to compute per-person share of operating costs. Rather, the average value of party size used was that derived for each origin-site combination in the data set. So in the computation of per-person share of operating costs, the variable NPIP could be as low as 1.0 , or perhaps as high as 5 or 6 , depending on the average party size.

Time deterrent cost, the other component of total unit cost of travel, is based on two assumptions. One, explained in the text, is that time spent traveling is valued at $\$ 2.67 /$ hour. The second is that average speed is 40 miles per hour. Traveling on straight roads could be faster; mountainous or dirt roads likely force slower travel. Our estimate of speed was agreed upon in consultation with Idaho Fish and Game personnel. Thus, the per-person time cost is computed as the quotient

$$
\frac{\mathrm{CPPH}}{\mathrm{SPED}}=\mathrm{PPTC}
$$

where $\mathrm{CPPH}=$ cost per person-hour

$$
\text { SPED = speed of vehicle on average }
$$

PPTC $=$ per person time cost.

Following these two computations (which are executed in the benefits computer program), the total cost per person per vehicle mile (CPVM) is the sum

$$
\mathrm{CPVM}=\mathrm{PPVC}+\mathrm{PPTC}
$$

As an example, consider the numbers used in this bulletin and assume that here, number of people in the party is 2.54 . The computation is

$$
\frac{\text { TCPM }}{\text { NPIP }}+\frac{\text { CPPH }}{\text { SPED }}=\text { CPVM }
$$

The standard cost in dollars per vehicle mile would be

$$
\frac{0.135}{2.54}+\frac{2.67}{40}=0.5315+0.06675=0.1199
$$

and the actual cost

$$
\frac{0.183}{2.54}+\frac{2.67}{40}=0.07205+0.066 .75=0.1388
$$





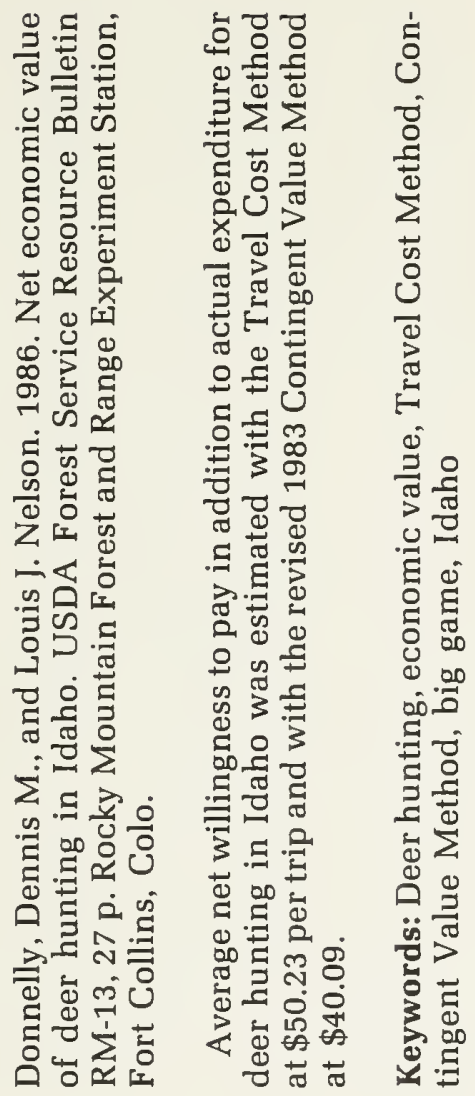

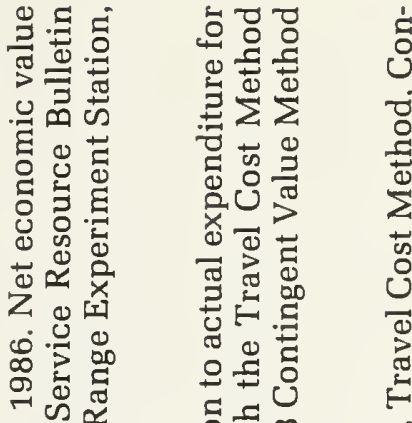

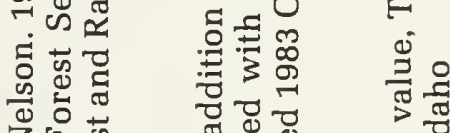

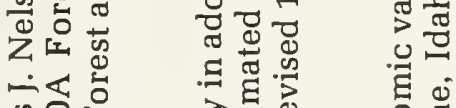

$\because$ 是

오.

踪

욜

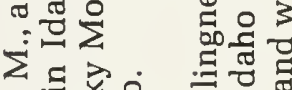

근 궁응

E 20

造实

之츨

蓎产

의

की

즁

了.․ㅡㄹ 焉

包

ช.

ฮี่

ऐ도용

䞨

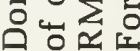

《苋需

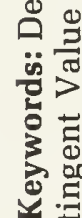

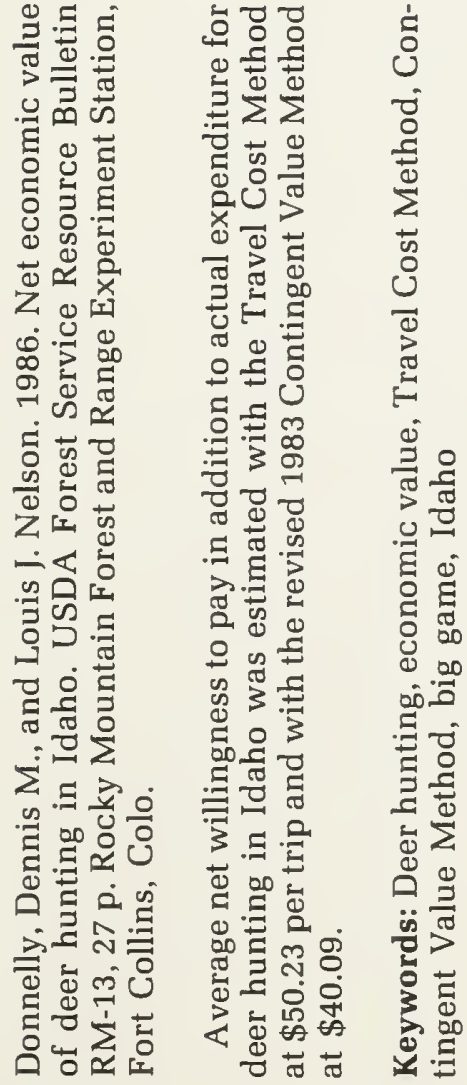

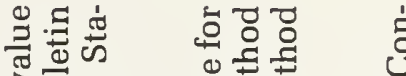

$>$ 元 导

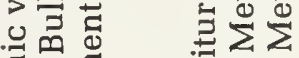

घี

焉

论

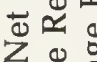

Z .

$\dot{\infty} \ddot{2}$

ब ळ

ธ่

क्षे ज़

乙江

我星

ชิ

○。

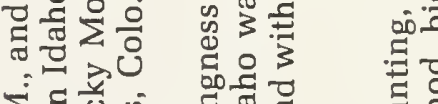

규유

焉

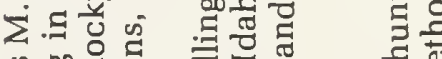

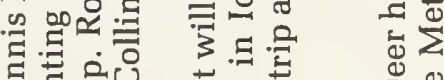

者讨 ब

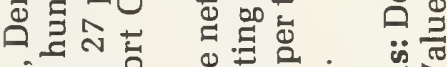

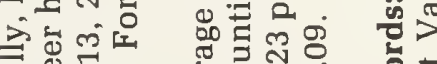

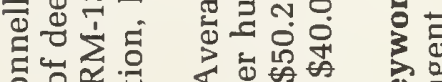

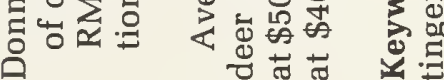






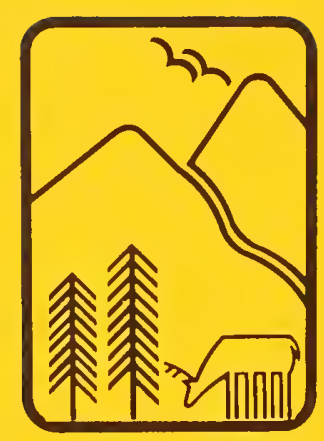

Rocky
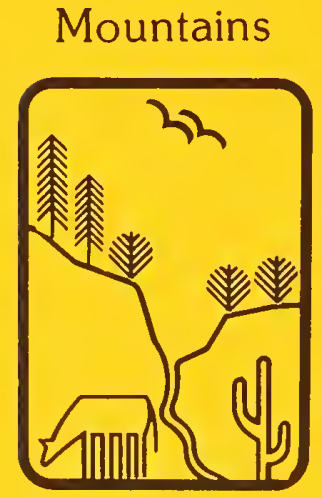

Southwest

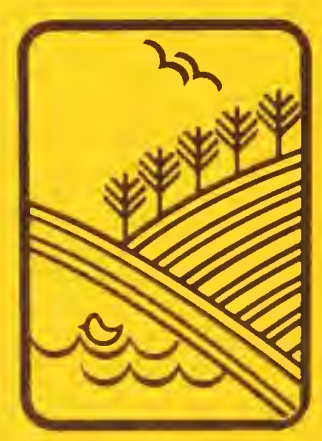

Great

Plains
U.S. Department of Agriculture Forest Service

\section{Rocky Mountain Forest and Range Experiment Station}

The Rocky Mountain Station is one of eight regional experiment stations, plus the Forest Products Laboratory and the Washington Office Staff, that make up the Forest Service research organization.

\section{RESEARCH FOCUS}

Research programs at the Rocky Mountain Station are coordinated with area universities and with other institutions. Many studies are conducted on a cooperative basis to accelerate solutions to problems involving range, water, wildlife and fish habitat, human and community development, timber, recreation, protection, and multiresource evaluation.

\section{RESEARCH LOCATIONS}

Research Work Units of the Rocky Mountain Station are operated in cooperation with universities in the following cities:

Albuquerque, New Mexico

Flagstaff, Arizona

Fort Collins, Colorado

Laramie, Wyoming

Lincoln, Nebraska

Rapid City, South Dakota

Tempe, Arizona

-Station Headquarters: 240 W. Prospect St., Fort Collins, CO 80526 